\title{
Article \\ Utility of a Short Neuropsychological Protocol for Detecting HIV-Associated Neurocognitive Disorders in Patients with Asymptomatic HIV-1 Infection
}

\author{
Martha Martinez-Banfi ${ }^{1, *}$, Jorge I. Vélez ${ }^{2} \oplus$, Moisés R. Mebarak Chams ${ }^{3}$, Mauricio Arcos-Holzinger ${ }^{4}$, \\ Johan E. Acosta-López ${ }^{1}\left(\mathbb{D}\right.$, Ricardo García ${ }^{5}$, María Victoria Perea ${ }^{5}$, Mauricio Arcos-Burgos 4 (D) and \\ Valentina Ladera ${ }^{5}$ (D) \\ 1 Facultad de Ciencias Jurídicas y Sociales, Universidad Simón Bolívar, Barranquilla 080005, Colombia; \\ jacosta@unisimonbolivar.edu.co \\ 2 Department of Industrial Engineering, Universidad del Norte, Barranquilla 081007, Colombia; \\ jvelezv@uninorte.edu.co \\ 3 Department of Psychology, Universidad del Norte, Barranquilla 081007, Colombia; \\ mmebarak@uninorte.edu.co \\ 4 Grupo de Investigación en Psiquiatría (GIPSI), Departamento de Psiquiatría, Instituto de Investigaciones \\ Médicas, Facultad de Medicina, Universidad de Antioquia, Medellín 050010, Colombia; \\ oscararcos98@gmail.com (M.A.-H.); mauricio.arcos@udea.edu.co (M.A.-B.) \\ 5 Facultad de Psicología, Universidad de Salamanca, 37008 Salamanca, Spain; rigar@usal.es (R.G.); \\ vperea@usal.es (M.V.P.); ladera@usal.es (V.L.) \\ * Correspondence: mmartinez108@unisimonbolivar.edu.co
}

Citation: Martinez-Banfi, M.; Vélez, J.I.; Mebarak Chams, M.R.; Arcos-Holzinger, M.; Acosta-López, J.E.; García, R.; Perea, M.V.; Arcos-Burgos, M.; Ladera, V. Utility of a Short Neuropsychological Protocol for Detecting HIV-Associated Neurocognitive Disorders in Patients with Asymptomatic HIV-1 Infection. Brain Sci. 2021, 11, 1037. https:// doi.org/10.3390/brainsci11081037

Academic Editor: Marco Cavallo

Received: 15 June 2021

Accepted: 29 July 2021

Published: 4 August 2021

Publisher's Note: MDPI stays neutral with regard to jurisdictional claims in published maps and institutional affiliations.

Copyright: (c) 2021 by the authors. Licensee MDPI, Basel, Switzerland. This article is an open access article distributed under the terms and conditions of the Creative Commons Attribution (CC BY) license (https:/ / creativecommons.org/licenses/by/ $4.0 /)$.

\begin{abstract}
Human Immunodeficiency Virus type 1 (HIV-1) infection is a chronic disease that affects $\sim 40$ million people worldwide. HIV-associated neurocognitive disorders (HAND) are common in individuals with HIV-1 Infection, and represent a recent public health problem. Here we evaluate the performance of a recently proposed short protocol for detecting HAND by studying 60 individuals with HIV-1-Infection and 60 seronegative controls from a Caribbean community in Barranquilla, Colombia. The short evaluation protocol used significant neuropsychological tests from a previous study of asymptomatic HIV-1 infected patients and a group of seronegative controls. Brief screening instruments, i.e., the Mini-mental State Examination (MMSE) and the International HIV Dementia Scale (IHDS), were also applied. Using machine-learning techniques, we derived predictive models of HAND status, and evaluated their performance with the ROC curves. The proposed short protocol performs exceptionally well yielding sensitivity, specificity, and overall prediction values $>90 \%$, and better predictive capacity than that of the MMSE and IHDS. Community-specific cut-off values for HAND diagnosis, based on the MMSE and IHDS, make this protocol suitable for HAND screening in individuals from this Caribbean community. This study shows the effectivity of a recently proposed short protocol to detect HAND in individuals with asymptomatic HIV-1-Infection. The application of community-specific cut-off values for HAND diagnosis in the clinical setting may improve HAND screening accuracy and facilitate patients' treatment and follow-up. Further studies are needed to assess the performance of this protocol in other Latin American populations.
\end{abstract}

Keywords: HIV; AIDS; HAND; neurocognitive disorder; predictive models; neuropsychological screening; machine learning

\section{Introduction}

Human Immunodeficiency Virus type 1 (HIV-1) infection is a chronic disease [1] that affects 37.9 million people worldwide [2]. HIV-associated neurocognitive disorders (HAND) are common in individuals with HIV-1 Infection [3,4], and represent a recent public health problem [5]. HAND is a neurocognitive impairment of attention, concentration, and memory domains, along with motor signs [6] that affect a patient's daily life. The HAND 
clinical profile follows the Frascati diagnostic criteria [7], and according to its severity, is categorized as Asymptomatic Neurocognitive Impairment (ANI), Mild Neurocognitive Disorder (MND), and HIV-Associated Dementia (HAD) [7]. Since the appearance of combined antiretroviral therapy (cART), HAD cases have declined (i.e., occurs in less than $5 \%$ of individuals undergoing cART), but MND remains frequent [3,8-10].

The neuropsychological evaluation represents a critical component of HAND diagnosis $[10,11]$. Several screening instruments and neuropsychological protocols are documented by the scientific literature, namely those proposed by the National Institute of Mental Health [12], the World Health Organization [13], the MACS [14], the CCWMS [15] and the HUMANS batteries [16]. More recently, batteries such as the Western Neuropsychological Test Battery of the HIV Neurobehavioral Research Center [11], and a battery developed by Brazilian researchers [17] are available. Although these comprehensive batteries are more sensible than screening tests $[11,18]$, the lack of access to them in environments with limited resources [19] increases the need to develop screening tools and short assessment protocols that facilitate HAND detection [20,21]. Some of these screening instruments include the Mini-mental State Examination (MMSE) (scrutinized for its low sensitivity) [8,9], the HIV Dementia Scale (HDS) [22], and the International HIV Dementia Scale (IHDS) [23] (with limited performance especially for the diagnosis of MND) [18,24,25], the Cognitive Assessment Tool-Rapid version (CAT-rapid) (with borderline sensitivity and low specificity) [8], the Montreal Cognitive Assessment (MOCA, with acceptable sensitivity but low specificity) [8], and the CogState computerized battery (with a sensitivity of $76 \%$ and specificity of $71 \%$, when compared to full neuropsychological testing) [21]. More recently, combinations of traditional [26] and short batteries of standard neuropsychological tests, which offer one of the best options to monitor the cognitive health of HIV+ individuals in clinics or research environments [27], have also been proposed as screening tests.

Despite this, a global consensus about which screening tools are most reliable is yet to be reached. This is partly due to specific differences in the cultural, economic, and linguistic training of evaluators, among other community aspects. Diagnostic tools should ideally have population-specific normative standards and evidence of cross-cultural validity for diagnostic reliability [28]. Additionally, applying full neuropsychological assessment would be ideal; however, in countries with less economic resources, these evaluations may not be available because of the cost and time required [29,30].

Good clinical practice suggests that early screening and follow-up of HAND with standardized tools [24] should be the routine assessment strategy for the cognitive performance of HIV patients [31]. Close monitoring of these patients would improve pharmacological treatments [18] and facilitate cognitive and behavioral interventions designed to improve the quality of life in HIV patients [5,17].

Clinical detection and HAND scrutiny with neuropsychological protocols can nurture new methods for prediction [20,32], which have recently been used in neuropsychological studies and have proven to be useful diagnostic tools in the clinical setting [33-35]. Among predictive models, machine learning (ML) algorithms showed an efficient performance to define HAND-specific treatment for individuals with advanced HIV [36,37]. One such algorithm is the Advanced Recursive Partitioning Approach (ARPA), widely used to build predictive tree-based ML models with Classification and Regression Tree (CART) analysis [38].

In this study, using ARPA, we assess the efficiency of a short version of a full neuropsychological protocol for HAND detection, recently proposed by our group [39]. We then compare it with other clinical screening instruments to define community-specific cut-off values for HAND diagnosis in individuals with asymptomatic HIV-1 Infection ascertained from a Caribbean community inhabiting Barranquilla, Colombia. 


\section{Subjects and Methods}

\subsection{Subjects}

We recruited and clinically evaluated 60 individuals with asymptomatic HIV-1 Infection and an equal number of seronegative controls. These individuals correspond to those involved in a previous study by our group [39]. The inclusion criteria for individuals with HIV-1 Infection were (i) a diagnosis of HIV-1 Infection in the asymptomatic stage; (ii) age ranging between 18 and $58 \mathrm{y} / \mathrm{o}$ (to control any potential age-related cognitive immaturity or decline) [24]; (iii) the completion of at least two years of elementary school; (iv) a maximum time since HIV diagnosis of 9 years (considering nine years is the maximum period HIV-1 infected individuals can remain asymptomatic) [40]; and (v) no history of alcohol and/or drug use, neurological, neuropsychological, and/or psychopathological disorders before HIV-1 diagnosis. The target population is primarily of low socioeconomic status, making it more vulnerable to develop HAND [19]. On the other hand, the control group accomplished the same criteria but was not infected with HIV. Table 1 shows the demographic characteristics of all individuals enrolled in this study. The mean time since diagnosis in the HIV-1 group was $3.32 \pm 2.5$ months, and $81.67 \%$ of the patients were on cART.

Table 1. Demographic characteristics of participants.

\begin{tabular}{|c|c|c|c|c|c|c|}
\hline Variable & Category & $\begin{array}{l}\text { All Individuals } \\
\quad(n=120)\end{array}$ & $\begin{array}{c}\text { Patients with } \\
\text { Asymptomatic HIV-1 } \\
(n=60)\end{array}$ & $\begin{array}{l}\text { Control Group } \\
\quad(n=60)\end{array}$ & Statistic & $p$ \\
\hline & & Mean \pm S.D. & Mean \pm S.D. & Mean \pm S.D. & $t(\mathrm{df})$ & \\
\hline Age (years) & & $36.07 \pm 10.98$ & $38.60 \pm 9.48$ & $33.53 \pm 11.84$ & 2.59 (118) & 0.011 \\
\hline \multirow[t]{2}{*}{$\begin{array}{l}\text { Years of } \\
\text { education }\end{array}$} & & $9.02 \pm 2.65$ & $8.07 \pm 2.85$ & $9.97 \pm 2.07$ & 4.18 (118) & $<0.0001$ \\
\hline & & $n(\%)$ & $n(\%)$ & $n(\%)$ & \multicolumn{2}{|l|}{$\chi^{2}(d f)$} \\
\hline Gender & $\begin{array}{l}\text { Female } \\
\text { Male }\end{array}$ & $\begin{array}{l}74(61.7) \\
46(38.3)\end{array}$ & $\begin{array}{l}32(53.3) \\
28(46.7)\end{array}$ & $\begin{array}{l}42(70) \\
18(30)\end{array}$ & $3.52(1)$ & 0.060 \\
\hline \multirow{2}{*}{$\begin{array}{c}\text { Sexual } \\
\text { orientation }\end{array}$} & Heterosexual & $111(92.5)$ & $53(88.3)$ & 58 (96.7) & \multirow[b]{2}{*}{$4.42(2)$} & \multirow[b]{2}{*}{0.109} \\
\hline & $\begin{array}{c}\text { Homosexual } \\
\text { Bisexual }\end{array}$ & $\begin{array}{l}5(4.2) \\
4(3.3)\end{array}$ & $\begin{array}{c}3(5) \\
4(6.7)\end{array}$ & $\begin{array}{c}2(3.3) \\
0(0)\end{array}$ & & \\
\hline \multirow[t]{2}{*}{$\begin{array}{c}\text { Hand } \\
\text { preference }\end{array}$} & Left & $6(5)$ & $0(0)$ & $6(10)$ & \multirow[t]{2}{*}{$6.32(1)$} & \multirow[t]{2}{*}{0.012} \\
\hline & Right & 114 (95) & $60(100)$ & $54(90)$ & & \\
\hline
\end{tabular}

Results significant at $5 \%$ are shown in bold. $d f$ = degrees of freedom; $\mathrm{SD}=$ Standard deviation. Note that HIV-1 infected and seronegative control groups differed in age and years of education.

\subsection{Short Neuropsychological Protocol for HAND Detection}

In a previous study by our group [39], a comprehensive neuropsychological gold standard battery was applied [7] to a group of individuals with asymptomatic HIV-1 Infection and a group of seronegative controls. Tests showing statistically significant differences between these groups were included in the short protocol considered in this study for HAND detection (Table 2). This protocol, described in detail in the Supplementary Material, includes neuropsychological tests used in similar studies in the U.S. [41], Germany [3], and Zambia [11], and categorized as 'useful' tools for HAND diagnosis [6], takes $\sim 1 \mathrm{~h}$ to be applied. Furthermore, it also includes a psychological test for anxiety, and it is essential to clarify that as part of the comprehensive neuropsychological battery previously applied in our sample [39], we included the evaluation of activities of daily living. However, no statistically significant difference was found between individuals with asymptomatic HIV-1 Infection and seronegative controls. Hence, this test was not included as part of the short neuropsychological protocol presented herein. Despite this, it is highly recommended to include it as part of the clinical examination. 
The standardized mental status examinations (MSEs) can be used with the appropriate demographically standardized cut-offs to evaluate HAND [7] during the early stages of the Infection [24], when full neuropsychological testing is not available. It is here where brief screening instruments, such as the Mini-mental State Examination (MMSE) [42] and the International HIV dementia scale (IHDS) [23], are widely used for HAND screening, especially in situations where there are time and resource limitations [5]. Although these are not part of our short protocol, these tests were also administered to all patients. Following standard guidelines, individuals scoring $\leq 26$ points in the MMSE were considered to have mild cognitive impairment [43], and those with an IHDS score of $\leq 10$ were subsequently evaluated for possible dementia [23].

To assess the HAND detection performance of our short neuropsychological protocol, and to compare it with the MMSE and IHDS screening tests, we defined HAND status according to three operational criteria: (1) MMSE $\leq 26$ [44], (2) IHDS $\leq 10$ [23], and (3) both MMSE $\leq 26$ and IHDS $\leq 10$-the latter determines whether the screening of cognitive impairment associated with both cortical and subcortical is present in HIV-1 infected individuals. Besides, we used the one-standard-deviation (1SD) criterion to assess suspicion of HAND in all patients [45]. This criterion translates into acquired impairment in cognitive functioning, involving at least two ability domains, based on age and education, and adjusted neuropsychological tests [45].

Table 2. Neurocognitive and psychological tests included in our proposed brief screening protocol for detecting HAND.

\begin{tabular}{|c|c|c|}
\hline $\begin{array}{l}\text { Neurocognitive and } \\
\text { Psychological Domain }\end{array}$ & Test & Conventions \\
\hline Attention span & Wechsler Memory Scale Digit Span Subtest [46] & $\begin{array}{l}\mathrm{T} 1=\text { Total score } \\
\mathrm{T} 2=\text { Direct Digit score }\end{array}$ \\
\hline Verbal learning and memory & Rey Auditory Verbal Learning Test $[47,48]$ & $\begin{array}{l}\mathrm{T} 5=\text { Trial } 3 \\
\mathrm{~T} 6=\text { Trial } 5 \\
\mathrm{~T} 7=\text { Total score in trials } 1 \text { to } 5\end{array}$ \\
\hline $\begin{array}{l}\text { Language } \\
\text { Phonemic verbal fluency }\end{array}$ & Controlled Word Association Test [49] & $\begin{array}{l}\mathrm{T} 12=\text { Total score } \\
\mathrm{T} 13=\text { Total score in letter " } \mathrm{P} \text { " } \\
\mathrm{T} 14=\text { Total score in letter " } \mathrm{M} \text { " }\end{array}$ \\
\hline Vocabulary & Wechsler Intelligence Scale Vocabulary Subtest [50] & $\mathrm{T} 3$ \\
\hline Naming & Boston Naming Test [51] & T9 = Phonemic clues \\
\hline Auditory-verbal comprehension & $\begin{array}{l}\text { Language Comprehension Subtest of the Brief } \\
\text { Neuropsychological Assessment in Spanish [52] }\end{array}$ & T19 \\
\hline Information processing speed & $\begin{array}{l}\text { Digit Symbol-Coding Subtest of the Wechsler } \\
\text { Intelligence Scale (WAIS-III) [50] }\end{array}$ & $\mathrm{T} 4$ \\
\hline Visuoconstructive skills & Rey Complex Figure Test [53] & $\mathrm{T} 8=$ Total direct score copy \\
\hline $\begin{array}{l}\text { Executive functions } \\
\text { Inhibition }\end{array}$ & Stroop Color-Word Test [54] & $\begin{array}{l}\text { T10 }=\text { Total score }(\text { word }) \\
\text { T11 }=\text { Total score }(\text { color })\end{array}$ \\
\hline Motor programming & $\begin{array}{l}\text { Motor Skills Subtest of the Brief } \\
\text { Neuropsychological Assessment in Spanish } \\
\text { (NEUROPSI) [52] }\end{array}$ & $\begin{array}{l}\text { T15 = Score in change of hand position } \\
\text { T16 = Score in alternating movements } \\
\text { of the two hands } \\
\text { T17 = Score in opposite reactions } \\
\text { T18 = Total score }\end{array}$ \\
\hline Anxiety & State-Trait Anxiety Inventory (STAI) [55] & $\begin{aligned} \text { T20 } & =\text { STAI }(\text { State }) \\
\text { T21 } & =\text { STAI }(\text { Trait })\end{aligned}$ \\
\hline
\end{tabular}

\subsection{Procedure}

Full neuropsychological tests were completed in two sessions and did not represent any risk for the participants since they only included pen-and-paper-based tests 
routinely used in the clinical practice. Informed written consent was obtained from all participants [39]. This study was carried out following local review board approval.

\subsection{Statistical Analysis}

All the data in this study were processed and analyzed using R version 3.5.0 [56]. Means, standard deviations (S.D.s), and range measures were used to summarize continuous variables such as age. Frequency and proportions were used to describe categorical variables such as gender and sexual orientation. We used the Advanced Recursive Partitioning Approach (ARPA) to construct a predictive tree-based ML model of HAND status using Classification and Regression Tree (CART) analysis [38] as implemented in the "rpart" package [57] for R. ARPA is widely used in predictive analyses as it accounts for (i) nonlinear hidden interactions better than other alternative methods, (ii) it is independent of the type of data and of the data distribution type, (iii) it offers fast solutions to reveal hidden complex substructures, and (iv) provides non-biased statistical analyses of highdimensional, seemingly unrelated data [58]. In our analysis, gender, age, years of education, HIV-1 infection status ( 0 = seronegative control; $1=$ HIV-infected), and variables collected in the neuropsychological battery were the predictors. A 5-fold cross-validation procedure was used to evaluate our ARPA-based predictive model of HAND for unobserved data. The performance of CART was assessed using the Receiver Operating Characteristic (ROC) curve [59] and the area under the ROC curve (AUC). The sensitivity $\left(S_{e}\right)$, specificity $\left(S_{p}\right)$, correct classification rate (CCR), positive predictive value (PPV), negative predictive value (NPV), false discovery rate (FDR), false-positive rate (FPR) and lift $[60,61]$ were used as additional criteria (Supplementary Tables S1 and S2).

We implemented an iterative procedure to derive community-specific cut-off values for the MMSE and IHDS for this population based on the ARPA-based predictive model for HAND. For illustration purposes, suppose we are interested in deriving the optimal cut-off for the MMSE. The procedure begins by partitioning the MMSE range in a sequence of $k$ equally spaced numbers such the sequence $x_{1}<x_{2}<x_{3}<\cdots<x_{k}$ is obtained, where $x_{1}$ and $x_{k}$ are, respectively, the minimum and maximum MMSE values in our cohort. Next, we define a "positive HAND screening" when MMSE $<x_{j}$, where $x_{j}$ is a particular value of the aforementioned sequence. The $S_{e}, S_{p}$, and CCR performance measures for the ARPA-based prediction model were further estimated using this diagnosis. The optimal cut-off value for the MMSE in this cohort, e.g., $x^{+}$, was defined as that maximum of both $S_{e}$ and $S_{p}$. A similar procedure was used to establish the optimal cut-off value for the IHDS.

\section{Results}

\subsection{Predictive Models for HAND Detection}

\subsubsection{HAND Detection Based on the 1SD Criterion}

Sixty individuals met the 1SD criterion for HAND (Table 3). We derived a four-level classification tree to predict HAND status (Figure 1a). This HAND ARPA-based model yielded $S_{e}, S_{p}, \mathrm{CCR}$, and AUC values above 0.9 for the full sample (Table 4), and includes the individual's age, the T10 (Total Score in the Word component of the Stroop's Color-Word Test), the T11 (Total Score in the Color component of the Stroop's Color-Word Test), the T18 (Total Score in the Motor Skills subtests of the NEUROPSI), the T19 (Score in the Language Comprehension Subtest of the NEUROPSI), and the T21 (State-Trait Anxiety Inventory [Trait]) tests as predictors (Figure 1a). Thus, individuals with scores T18 $<7.5$ have a $69 \%$ chance of HAND affection (that is, $67 \%$ of our sample; node 3 ). This figure reduces to $54 \%$ when, in addition, individuals score 5.5 or more in T19 (that is, $42 \%$ of our sample; node 6), and dramatically increases to $93 \%$ when individuals score less than 5.5 in this latter test (that is, $25 \%$ of our sample; node 7 ). Interestingly, individuals 46 y/o or younger, scoring at least 7.5 points in the T18, at least 5.5 points in the T19, more than 32 points in the T21, and less than 6.5 points in the T18, have a 95\% chance of HAND affection (18\% of our sample) (Figure 1a and Table 3). Comparison of the ROC curves (Figure 1b, left) and performance measures (Table 4) show that our proposed short protocol outperforms other 
HAND-detection neuropsychological instruments in our sample; the T18, T15, and T11 tests seem to be the most important variables for HAND diagnosis (Figure 1b, right).

Table 3. Number of individuals with HAND based on the short screening protocol following Frascati 1SD criterion, along with the ARPA-based predicted HAND diagnosis by HIV-1 infection status. Here, age, sex, years of education, and tasks comprising our short screening protocol were included as predictors.

\begin{tabular}{|c|c|c|c|c|}
\hline \multirow{2}{*}{$\begin{array}{l}\text { Asymptomatic HIV-1 } \\
\text { Infection }\end{array}$} & \multirow{2}{*}{$\begin{array}{c}\text { ARPA-Based } \\
\text { Predicted HAND }\end{array}$} & \multicolumn{2}{|c|}{ HAND Diagnosis } & \multirow{2}{*}{ Total } \\
\hline & & No & Yes & \\
\hline \multirow{2}{*}{ No } & No & 56 & 0 & 56 \\
\hline & Yes & 4 & 0 & 4 \\
\hline \multirow{2}{*}{ Yes } & No & 0 & 5 & 5 \\
\hline & Yes & 0 & 55 & 55 \\
\hline
\end{tabular}

a

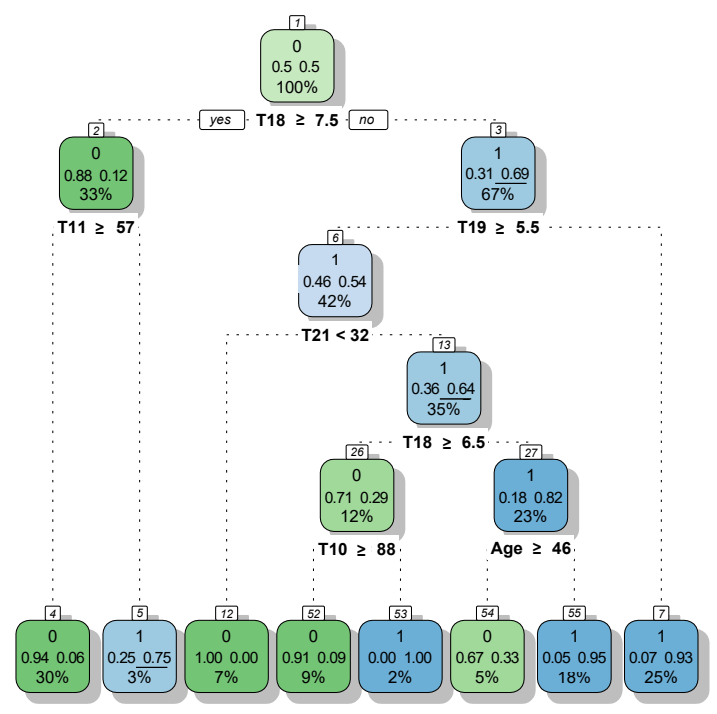

b
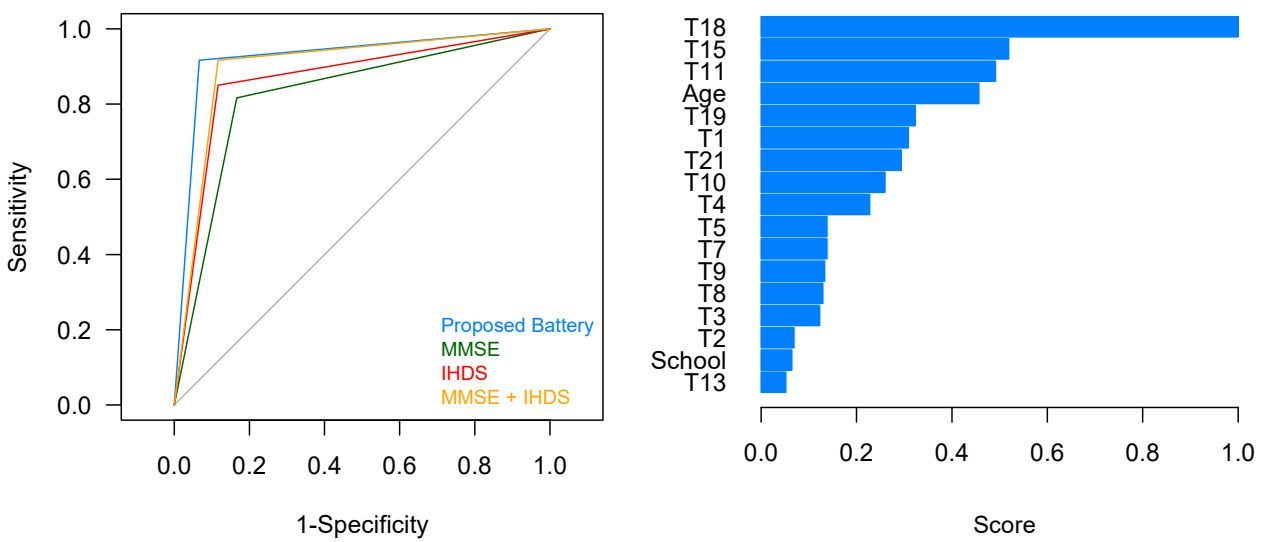

Figure 1. Results of the ARPA-based predictive model for HAND screening. (a) Classification tree derived using the CART strategy. HAND status was defined using 1 S.D. below the normative data and predicted using the proposed neuropsychological battery. Numbers within white squares represent the node number; the first line corresponds to the most frequent class (0: Unaffected; 1: HAND affected), the second line to the probability of each class within the node, and the third line to the percentage of the total sample size $(n=120)$ within each node. Nodes where HAND-affected individuals are more likely to be classified are shown in blue. (b) (left) ROC curves when HAND status was predicted using the ARPA-based model, including the proposed battery, MMSE, IHDS, and both MMSE and IHDS. (right) Variable importance for the derived predictive model based on the proposed battery. ARPA: Advanced recursive partitioning approach; CART: Classification and regression tree; ROC: Receiver operating characteristic. School: Years of education. Here, T1, T2, ... , T21 correspond to the neuropsychological and psychological tests. See Table 2 for more details. 
Table 4. Performance measures when different instruments are used in the ARPA-based predictive model of HAND. Overall, the proposed battery performs better than other instruments also evaluated. Here, $a$ is the number of individuals with HAND that are correctly classified, $b$ is the number of HAND individuals classified as controls, $c$ corresponds to the number of control individuals classified as HAND, and $d$ to the number of control individuals correctly classified. $S_{\mathrm{e}}=$ sensitivity; $S_{\mathrm{p}}=$ specificity; PPV = positive predictive value; NPV = negative predictive value; FDR = false discovery rate; $\mathrm{FPR}=$ false positives rate; $\mathrm{CCR}=$ Correct classification rate (Accuracy); $\mathrm{AUC}=$ area under the ROC curve (Figure $1 \mathrm{~b}$ ). See Supplementary Table S1 for expressions to calculate these performance measures form $a, b, c$, and $d$.

\begin{tabular}{cccccccccccccc}
\hline Instrument & $\boldsymbol{a}$ & $\boldsymbol{b}$ & $\boldsymbol{c}$ & $\boldsymbol{d}$ & $\boldsymbol{S}_{\mathbf{e}}$ & $\boldsymbol{S}_{\mathbf{p}}$ & $\mathbf{P P V}$ & $\mathbf{N P V}$ & FDR & FPR & CCR & Lift & AUC \\
\hline Short Protocol & 55 & 4 & 5 & 56 & 0.917 & 0.933 & 0.932 & 0.918 & 0.068 & 0.067 & 0.925 & 1.864 & 0.925 \\
MMSE & 50 & 11 & 10 & 49 & 0.833 & 0.817 & 0.820 & 0.831 & 0.180 & 0.183 & 0.825 & 1.639 & 0.825 \\
IHDS & 53 & 9 & 7 & 51 & 0.883 & 0.850 & 0.855 & 0.879 & 0.145 & 0.150 & 0.867 & 1.710 & 0.867 \\
MMSE + IHDS & 53 & 5 & 7 & 55 & 0.883 & 0.917 & 0.914 & 0.887 & 0.086 & 0.083 & 0.900 & 1.828 & 0.900 \\
\hline
\end{tabular}

\subsubsection{HAND Detection Based on the MMSE and IHDS Operational Criteria}

Based on the MMSE criterion, we found no seronegative controls with suspicion of HAND, and a total of nine individuals with HIV-1 Infection were identified with suspicion of HAND (Table 5). The average MMSE differed between groups (HIV: $27.55 \pm 1.9$, control: $29.05 \pm 1.11 ; p=0.002)$.

Table 5. Number of individuals with HAND and ARPA-based predicted HAND diagnosis by HIV1 infection status. HAND diagnosis was defined according to three different criteria. For each criterion, age, sex, years of education, and tasks comprising our short screening protocol were used as predictors in the ARPA-based model.

\begin{tabular}{|c|c|c|c|c|}
\hline \multicolumn{5}{|c|}{ Criterion 1: MMSE in $(10,25]$} \\
\hline \multirow{2}{*}{$\begin{array}{l}\text { Asymptomatic } \\
\text { HIV-1 Infection }\end{array}$} & \multirow{2}{*}{$\begin{array}{l}\text { Predicted } \\
\text { HAND }\end{array}$} & \multicolumn{2}{|c|}{ HAND Diagnosis } & \multirow{2}{*}{ Total } \\
\hline & & No & Yes & \\
\hline \multirow[b]{2}{*}{ No } & No & 60 & 0 & 60 \\
\hline & Yes & 0 & 0 & 0 \\
\hline \multirow{2}{*}{ Yes } & No & 50 & 4 & 54 \\
\hline & Yes & 1 & 5 & 6 \\
\hline \multicolumn{5}{|c|}{ Criterion 2: IHDS $<11$} \\
\hline \multirow{2}{*}{ No } & No & 38 & 2 & 40 \\
\hline & Yes & 8 & 12 & 20 \\
\hline \multirow{2}{*}{ Yes } & $\mathrm{No}$ & 22 & 5 & 27 \\
\hline & Yes & 2 & 31 & 33 \\
\hline \multicolumn{5}{|c|}{ Criterion 3: MMSE in $(10,25]$ and IHDS $<11$} \\
\hline \multirow{2}{*}{ No } & No & 60 & 0 & 60 \\
\hline & Yes & 0 & 0 & 0 \\
\hline \multirow{2}{*}{ Yes } & No & 52 & 1 & 53 \\
\hline & Yes & 0 & 7 & 7 \\
\hline
\end{tabular}

A two-node classification tree to predict HAND affection status was derived (Figure 2a). This tree is composed of the T4 (Digit Symbol-Coding Subtest of the Wechsler Intelligence Scale) and the T18 (Total Score in the Motor Skills subtests of the NEUROPSI) neuropsychological tests. Thus, individuals with scores T4 $<30$ and T18 $<3.5$ have an $83 \%$ chance of HAND diagnosis when the MMSE criterion is used (that is, $5 \%$ of our sample), and it correctly classifies 5/9 (55.5\%) individuals initially identified as suspected of HAND, based on the MMSE criterion, leading to $S_{e}=0.55, S_{p}=0.99, \mathrm{CCR}=0.958$, and AUC $=0.723$ (Figure 2a and Table 5). 
a
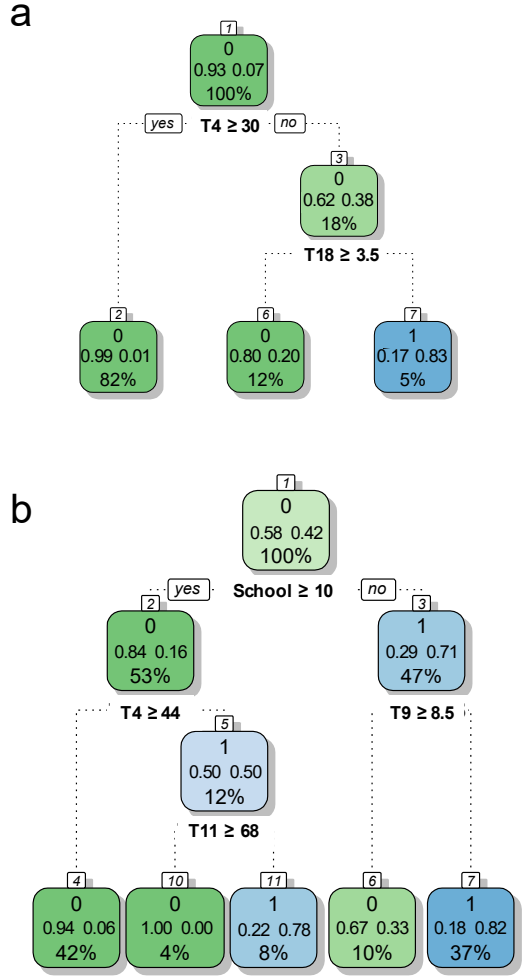

C

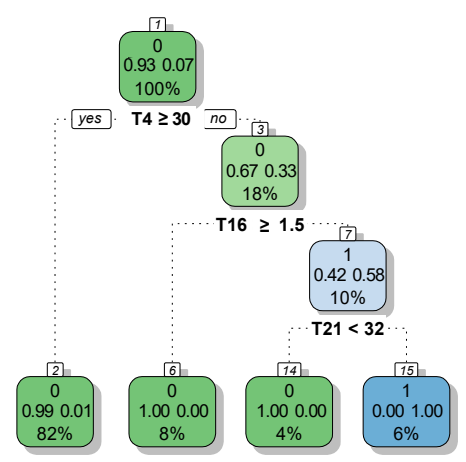

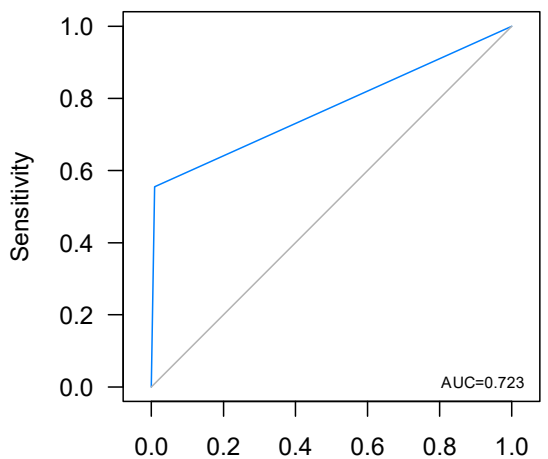
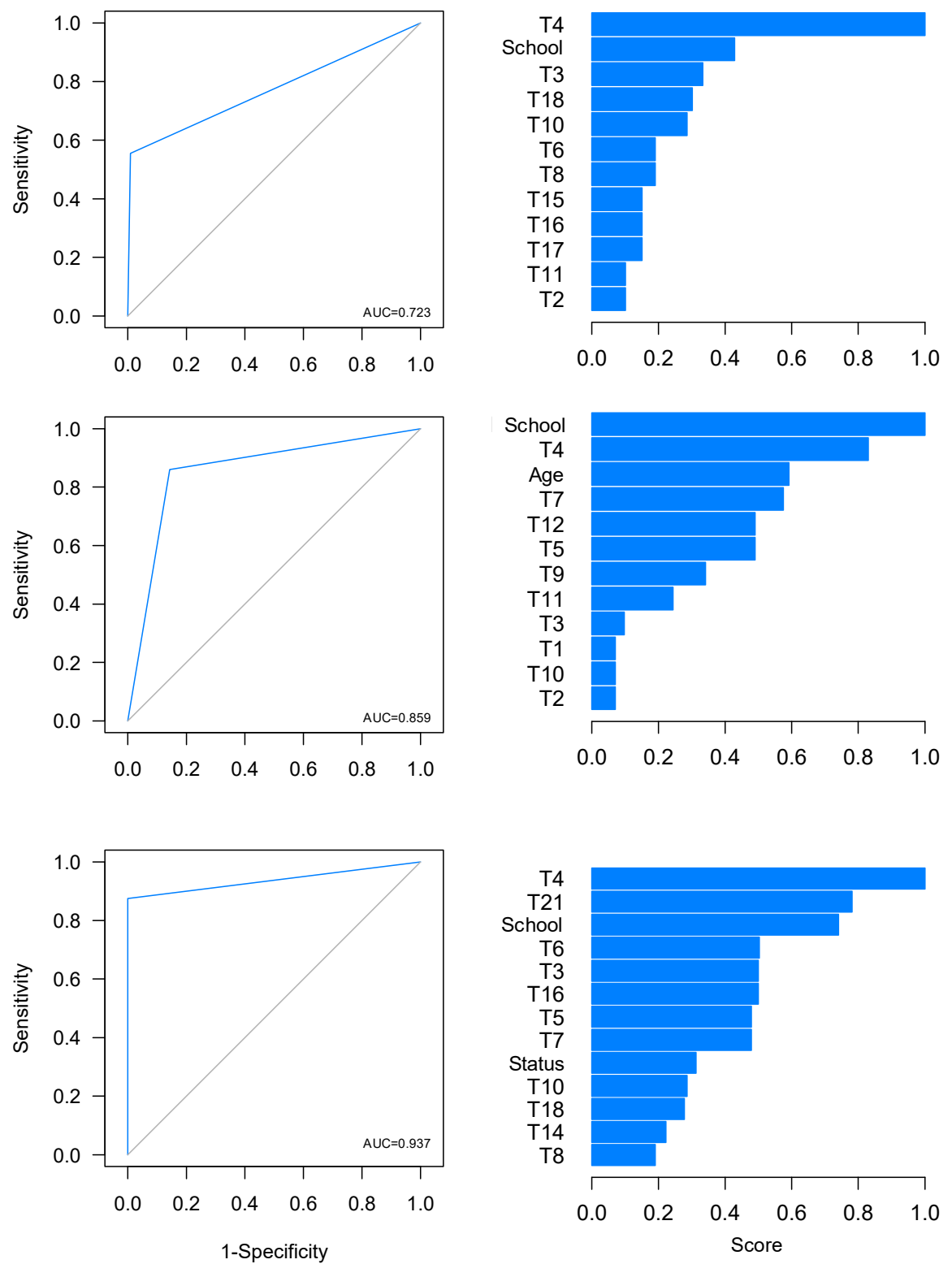

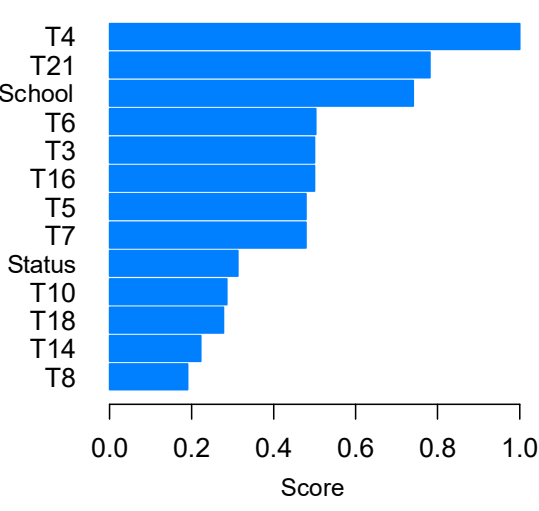

Figure 2. Results of the ARPA-based predictive model for HAND screening in individuals with HIV-1 Infection from the Colombian Caribbean. The HAND status was defined using (a) MMSE < 26, (b) IHDS $\leq 10$, and (c) both MMSE < 26 and IHDS $\leq 10$ (see Methods). (left) The classification tree derived using the CART strategy. Status: HIV-1 Infection status (0: control; 1: case). Other conventions as in Figure 1.

Using the IHDS criterion, 50 individuals met the criteria for HAND (36 with HIV-1 Infection and 14 seronegative controls) (Table 5). The mean IHDS differed between the two assessed groups (HIV: $9.79 \pm 1.97$, control: $11.02 \pm 1.21 ; p=0.001$ ). Our ARPA-based predictive model corresponds to a three-level tree and includes the years of education, the T4, the T11 (total score in the Color Component of the Stroop's color-word test), and the T19 (score in the Language Comprehension Subtest of the NEUROPSI) neuropsychological tests as predictors. This predictive model correctly identifies 12/14 (86\%) seronegative individuals diagnosed with suspicion of $\operatorname{HAND}\left(S_{e}=0.877, S_{p}=0.826, \mathrm{CCR}=0.833\right)$, and $31 / 36(86.1 \%)$ individuals with HIV-1 infection meeting the IHDS criterion for HAND $\left(S_{e}=0.861, S_{p}=0.917, \mathrm{CCR}=0.883\right)$. Overall, the model correctly classifies $43 / 50$ individuals $\left(86 \%\right.$; 31 with HIV-1 infection), leading to $S_{e}=0.86, S_{p}=0.857, \mathrm{CCR}=0.858$, and AUC $=0.859$ (Figure $2 \mathrm{~b}$ and Table 4 ). Thus, individuals with less than ten years of education have a $71 \%$ chance of HAND affection ( $47 \%$ of the total sample); this figure increases to 
$82 \%$ if less than 8.5 points are obtained in T9 (37\% of the total sample). Besides, individuals with more than ten years of education, $<44$ points in $\mathrm{T} 4$, and $<68$ points in T11, have a $78 \%$ chance of HAND affection using the IHDS criterion ( $8 \%$ of the total sample). Unlike in the MMSE criterion (Figure 2a), both years of education and the individuals' age are seemingly important predictors of HAND status when used by the IHDS criterion.

Finally, if both the MMSE and the IHDS operational criteria are used for screening to define HAND suspects, eight individuals in our sample (seven with HIV-1 Infection) met the diagnosis criteria (Table 5). We derived a three-level classification tree with three splitting nodes; these nodes correspond to the T4, the T16 (Score of the Motor Skills 2 subtest of the NEUROPSI), and the T21 tests (Figure 2c). Interestingly, our neuropsychological short protocol correctly identifies suspicion of HAND in 57/58 (98.3\%) individuals with HIV-1 infection $\left(S_{e}=0875, S_{p}=1, \mathrm{CCR}=0.983, \mathrm{AUC}=0.937\right)$ (Figure $2 \mathrm{c}$ and Table 5). Thus, individuals with $<30$ points in T4 and $<1.5$ points in T16 have a $58 \%$ chance of HAND $(10 \%$ of the total sample); besides, this figure increases to $100 \%$ when more than 32 points are obtained in $\mathrm{T} 21$.

\subsection{Specific Cut-Off Values for HAND Screening in This Caribbean Community}

In our sample, the MMSE Score ranged from 23 to 29, and the IHDS score ranged from 3.5 to 12.5. Using the iterative process outlined in the methods section, we identified that MMSE $<27$ (Figure 3 and Table 6) and IHDS $<10$ (Figure 3 and Table 6) are the optimal cut-off values for screening suspicion of HAND in this Caribbean community.

Table 6. Number of individuals with HAND and ARPA-based predicted HAND diagnosis by HIV1 infection status using the derived community-specific cut-off values for the MMSE and IHDS. HAND diagnosis was defined according to the community-specific cutoff values. Age, sex, years of education, and the neuropsychological tasks comprising our short screening protocol were used as predictors in the ARPA-based model.

\begin{tabular}{|c|c|c|c|c|}
\hline \multicolumn{5}{|c|}{ MMSE $<27$} \\
\hline \multirow{2}{*}{$\begin{array}{l}\text { Asymptomatic } \\
\text { HIV-1 Infection }\end{array}$} & \multirow{2}{*}{$\begin{array}{l}\text { Predicted } \\
\text { HAND }\end{array}$} & \multicolumn{2}{|c|}{ HAND Diagnosis } & \multirow{2}{*}{ Total } \\
\hline & & No & Yes & \\
\hline \multirow{2}{*}{ No } & No & 57 & 0 & 57 \\
\hline & Yes & 1 & 2 & 3 \\
\hline \multirow{2}{*}{ Yes } & No & 43 & 1 & 44 \\
\hline & Yes & 3 & 13 & 16 \\
\hline \multicolumn{5}{|c|}{ IHDS $<10$} \\
\hline \multirow{2}{*}{ No } & No & 51 & 1 & 52 \\
\hline & Yes & 1 & 7 & 8 \\
\hline \multirow{2}{*}{ Yes } & No & 30 & 2 & 32 \\
\hline & Yes & 4 & 24 & 28 \\
\hline
\end{tabular}




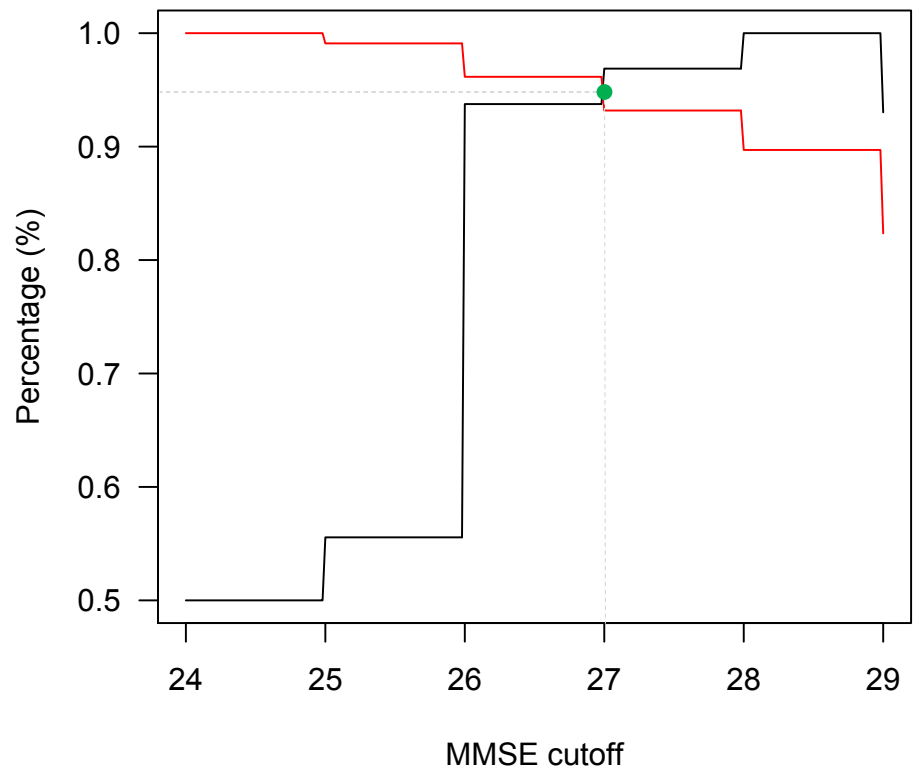

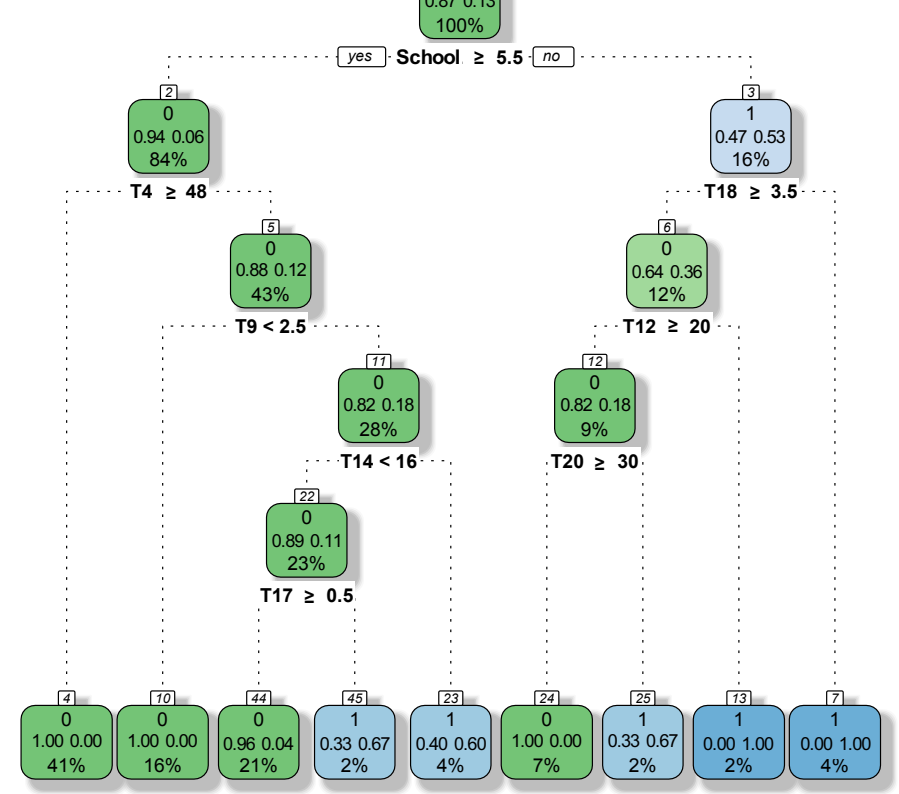
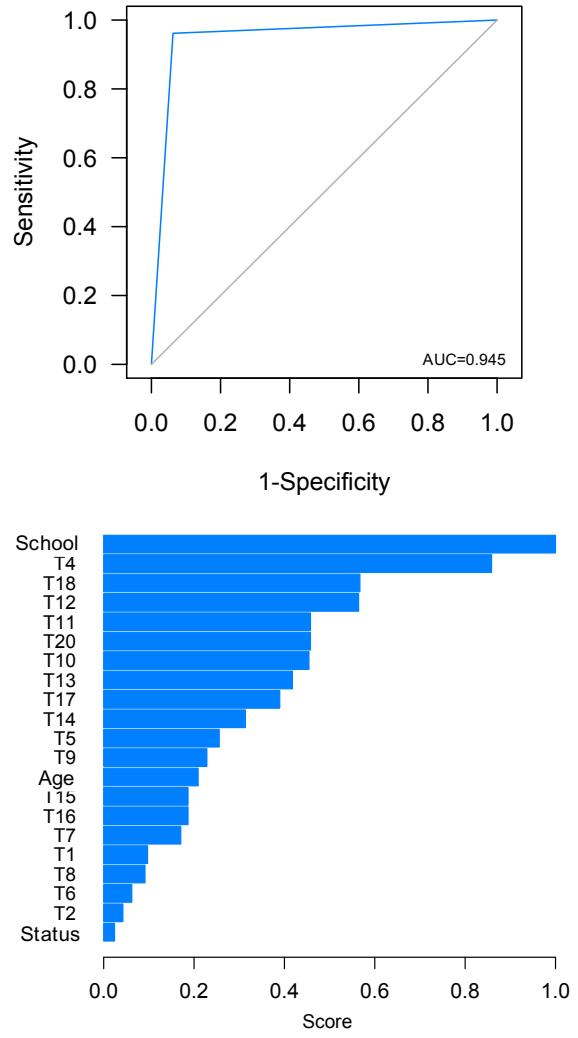

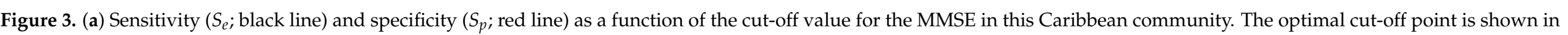

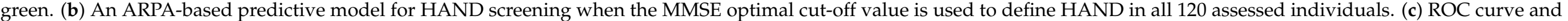
variable importance for the derived model. Status: HIV-1 Infection status (0: control; 1: case). Other conventions as in Figure 1. 
When using an MMSE cut off value of $<27,16$ individuals with suspicion of HAND are identified (14 with HIV-1 Infection; Table 6). Our predictive model for HAND status includes the T4, T9, T12 (Total Score in the Controlled Word Association Test [CWAT]), T14 (letter "M" Score of the CWAT), the T17 (Score of the Motor Skills 3 subtest of the NEUROPSI), T18 (Total Score in the Motor Skills subtests of the NEUROPSI), and T20 (Score of the State-Trait Anxiety Inventory [State]). This ARPA-based predictive model of HAND status yielded $S_{e}=0.937, S_{p}=0.962, \mathrm{CCR}=0.958$, and $\mathrm{AUC}=0.949$ for the whole sample, with similar results when only individuals with HIV-1 infection are considered $\left(S_{e}=0.875\right.$, $S_{p}=1, \mathrm{CCR}=0.983, \mathrm{AUC}=0.937$ ) (Figure 3 and Table 6). In particular, individuals with less than 5.5 years of education have a 53\% chance of being diagnosed with HAND (16\% of the total sample; Figure 3); this figure increases to $100 \%$ when, in addition, individuals obtain either $<3.5$ points in T18 (4\% of our sample) or less than 20 points in T12 ( $2 \%$ of our sample). On the other hand, individuals with $<5.5$ years of education, T18 $\geq 3.5, \mathrm{~T} 12 \geq 20$, and T20 < 30 have a $67 \%$ chance of being diagnosed with HAND ( $2 \%$ of the sample). It is noteworthy that, in this model, years of education seems to be the most important variable when defining a HAND suspect.

At IHDS < 10, 34 individuals with suspected HAND are identified (26 with HIV infection; Table 6). Our predictive model includes age and the T2 (direct digits score of the Wechsler Memory Scale Digit Span subtest), T3 (Score of the Wechsler Intelligence Scale Vocabulary subtest), T4, T6 (Trial 5 of the Rey Auditory Verbal Learning Test), T18, and T21 tests as predictors of HAND status (Figure 4). This predictive model yields $S_{e}=0.912, S_{p}=0.942, \mathrm{CCR}=0.933$, and AUC $=0.927$ in all 120 individuals, with similar performance measures for HIV-1 infected $\left(S_{e}=0.923, S_{p}=0.882, \mathrm{CCR}=09.9, \mathrm{AUC}=0.903\right)$ and seronegative $\left(S_{e}=0.875, S_{p}=0.981, \mathrm{CCR}=0.967, \mathrm{AUC}=0.928\right)$ individuals separately (Figure 4 and Table 6). Thus, individuals with $<48$ points in T4, and 28 years or older have a $57 \%$ chance of being classified as suspicion of HAND (48\% of our sample). This figure increases to $73 \%$ when, in addition, individuals obtain less than 6.5 points in T18 (31\% of our sample) and to $90 \%$ when individuals obtain more than 14 or more points in T3 (18\% of our sample) (Figure 4). 

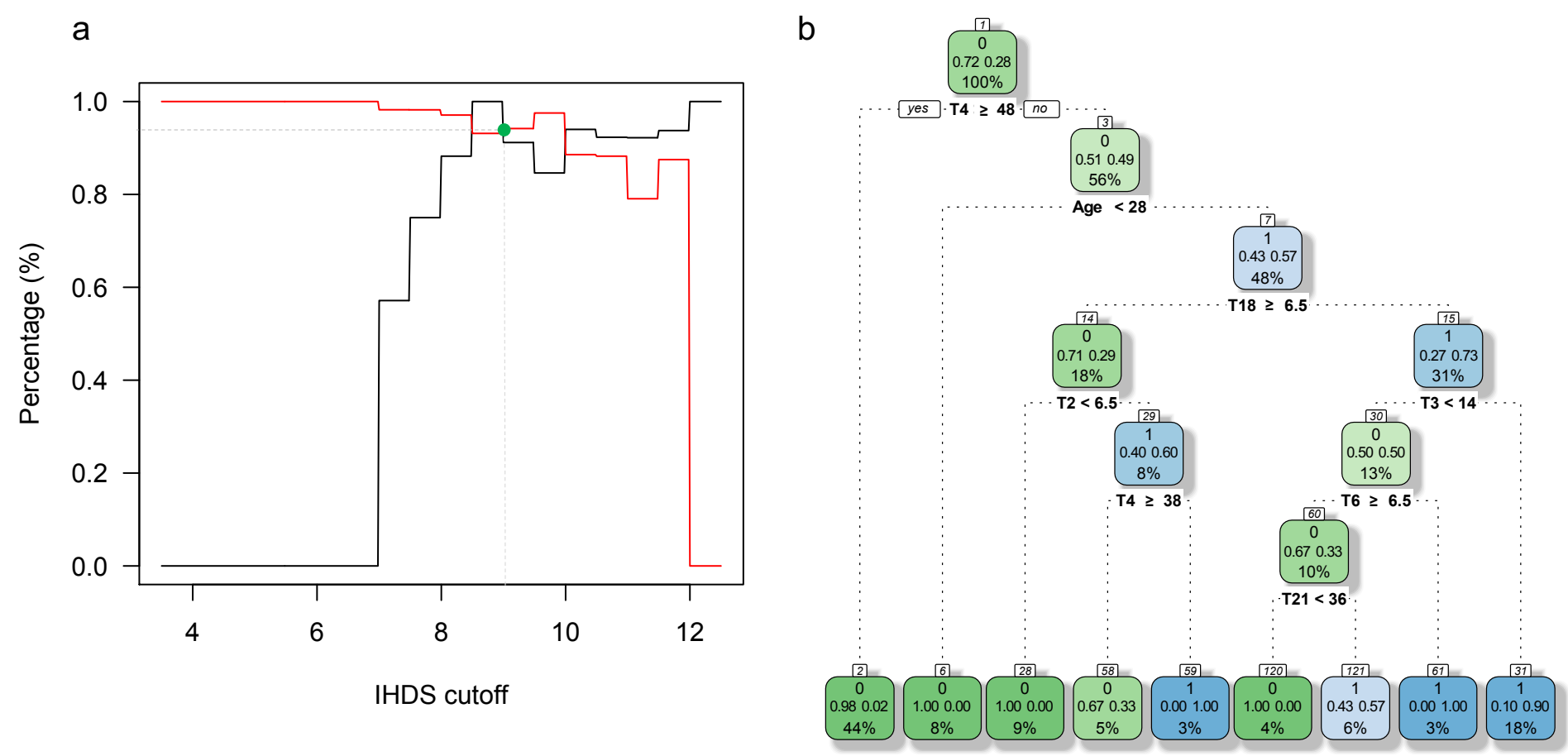

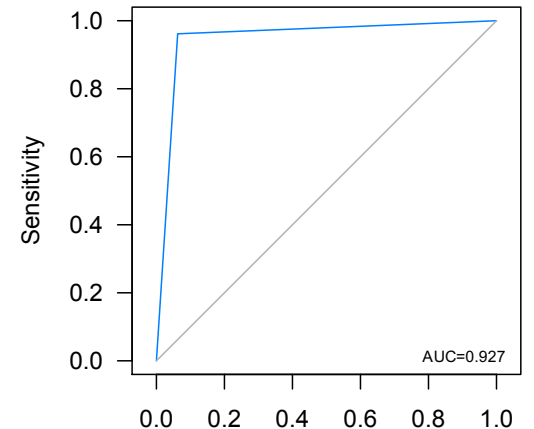

1-Specificity

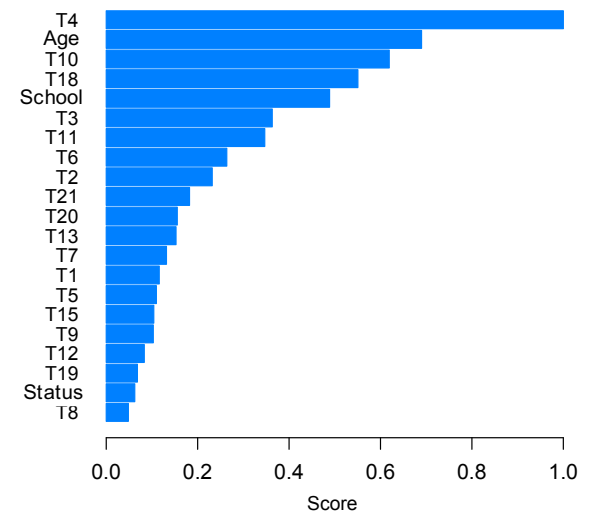

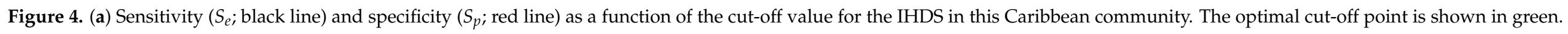

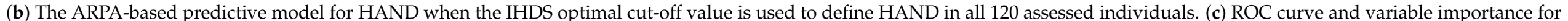
the derived model. Other conventions as in Figure 1. 


\section{Discussion}

The detection and better understanding HAND accurately are critical for the clinical management of patients who suffer from this disorder [11]. In this study, we proposed a short neuropsychological protocol to detect HAND and evaluated its performance in individuals with asymptomatic HIV-1 Infection from an Afro-Colombian community in Barranquilla, Colombia. Our results show that our short neuropsychological protocol outperforms other instruments used for the same purpose in the clinical setting (Figure $1 \mathrm{~b}$ and Table 4), such as the UCSD Performance-Based Skills Assessment (UPSA-B), which only has an accuracy of $71 \%$ when identifying HIV-1 infected individuals with neurocognitive impairment [62]. With the results obtained, we suggest that our short protocol could be a plausible evaluation tool for accurate HAND detection in clinical practice. Although our protocol is neither a screening test nor a full battery, it resembles other universally used standard neuropsychological tests that are sensitive in screening and monitoring for HAND [29], especially for mild HIV-related neurocognitive impairment [26]. It also allows for a more complete and time-effective evaluation in about $1 \mathrm{~h}$, which makes it appealing in the clinical setting. Importantly, the ability of our short neuropsychological protocol for HAND screening in individuals with asymptomatic HIV-1 Infection highlights its importance to early diagnoses milder forms of HAND.

Highlighting the importance of some neuropsychological tests in our protocol is crucial in understanding the breakdown of such (Figures 1-4). Namely, the Digit SymbolCoding Subtest of the Wechsler Intelligence Scale (WAIS-III) [63], the Motor Skills Subtest of the Brief Neuropsychological Assessment in Spanish (NEUROPSI), the phonemic clues subtest of the Boston Naming Test, and the Controlled Word Association Test are designed to identify alterations in the speed of processing information, motor skills, and executive functions and are highly appropriate with the clinical description in HAND [64-68]. In addition to neuropsychological testing, the State-Trait Anxiety Inventory's (STAI) ability to assess anxiety as part of the clinical features in HAND has previously been emphasized [69]. Furthermore, considering that age is a risk factor for HAND [70], it is noteworthy that age and years of education are essential variables to predict HAND in this population (Figures 1-4). These variables may correspond to an early-stage profile of neurocognitive impairment (NCI) of the subcortical type, characterized by slower cognitive processes and reflected in attention, concentration, and executive function [6,71].

HAND diagnosis is not straightforward due to the existence of other clinical factors associated with HIV-1 infection [4,72,73] such as virus subtypes (clades) [74], high viral load, and low CD4 counts [75], HAND-associated risk factors [76,77], long-term exposure to cART [78], comorbidities $[31,79,80]$, sociocultural/ethnic backgrounds $[15-17,64]$ and genetic factors [81,82]. Interestingly, compared to using the proposed neuropsychological protocol, including CD4 counts as a predictor does not significantly improve the accuracy of the ARPA-based predictive model of HAND in patients with asymptomatic HIV-1 infection (Figure S1) Therefore, a straightforward neuropsychological evaluation for HAND is crucial to the diagnosis [24], and it is important to strengthen and unify methods of screening to assess milder to severe manifestations of HAND efficiently. It also allows for a more effective follow up of patients using evaluations emphasizing clinical variables associated with this neurocognitive disorder $[64,83]$. These new processes should be considered as part of the integrative care of individuals with HIV-1 Infection and therefore included in the routine clinical HIV management [84].

We found that our ARPA-based HAND predictive model, involving the MMSE criterion (Figure 1a), yielded outstanding specificity and correct classification rates, but low-to-average specificity and AUC (Table 4). Thus, we advise against using this criterion to define HAND in individuals with asymptomatic HIV-1 Infection. Low performance in the MMSE might be indicative of a possible neurocognitive impairment (NCI) of cortical origin [85], which is present in more advanced HAND states [86], and it is also associated with more advanced stages of the Infection [86,87]. It could partially explain why our clinical protocol detects more HAND cases among individuals with asymptomatic HIV-1 
Infection. Furthermore, it is highly likely that one would not expect a more significant neurocognitive compromise because of the asymptomatic nature of the Infection. Frontal white matter compromise has been demonstrated in ANI, while a more widespread subcortical atrophy has been found in MND [88]. However, individuals with HIV-1 Infection, where HAND was detected, could have more severe clinical characteristics that potentially explain the neurocognitive compromise. These results may also be a consequence of the low sensitivity of the MMSE to detect HAND, especially in the early stages [3,89-91].

The IHDS is a useful tool to screen HAND [3,10]; it has a higher sensitivity to detect HAD [8,18], but performs poorly to detect milder forms of HAND [89]. This scale should be preferred in situations where sensitivity is more important at the expense of its loss of specificity [25], and as a screening tool in scenarios with limited resources [23]. In our sample, the IHDS correctly identifies what seems to be milder forms of HAND because there is no compromise of daily living activities [7] (Figure 1b, Figure 2b, and Table 4). Thus, our findings support the use of the IHDS to detect milder forms of HAND [63].

We also found that when using the IHDS-based operational criterion as a screening tool for HAND, most of the diagnoses were assigned to individuals with HIV-1 Infection (Figure $2 b$ and Table 5). It implies a higher sensitivity of this criterion to identify the HAND of subcortical origin, which corresponds to the early stages [6]. Although the IHDS was specifically designed to identify this NCI profile in individuals with HIV-1 Infection [23], our IHDS-based screening tool (Figure 2b) also detects 14 seronegative individuals who, in principle, are not affected by NCI (Table 5). This result may be a consequence of the previously reported lack of specificity of the IHDS [25], and could also be explained by the sociodemographic characteristics of this Caribbean community [23], associated with elements of the acculturation which can affect neuropsychological functioning [92].

Although the MMSE and IHDS screening tools were designed to assess the brief cognitive state, the performance of this combined HAND screening tool outperforms that of either the MMSE (Figure 2a and Table 5) or IHDS (Figure 2b and Table 5) criterion. One possible explanation is that the MMSE + IHDS operational criterion is effectively assessing different cognitive functions. It means that one test does not substitute the other, and their combination improves HAND diagnostic accuracy [5]. Thus, we strongly advocate for a multidisciplinary approach to HAND [93] where pathophysiological biomarkers [94], neurological and psychiatric differential diagnosis [95], and other confounding variables [7], together with a neuropsychological assessment, comprise the ideal set of tools for the diagnosis of HAND.

Most research studies on HAND and its diagnosis have been conducted in North America, Europe, and Africa, with very few studies in Latin America. To the best of our knowledge, there are no available neuropsychological protocols for HAND detection in Colombia, let alone communities belonging to this geographical area (with specific patterns of ancestry and cultural background) [96]. Following the recommendations of experts $[18,97]$, and considering the relevance of an early HAND diagnosis in individuals with HIV-1 Infection, one of the strengths of this study is the proposal of a short protocol that could be applied in approximately $1 \mathrm{~h}$, is comprised by standardized tests widely used in different countries around the world, and has the potential to detect HAND from the asymptomatic stage of the HIV-1 infection. Thus, the ARPA-based predictive models of HAND are presumably closer to the diagnosis or screening of a milder form of HAND. Our results suggest that all derived models based on the neuropsychological battery previously reported (Table 2 and Supplementary Material) could be a suitable HAND detection tool in the clinical practice and may help in the early detection and follow-up of individuals with asymptomatic HIV-1 Infection who are at risk of developing HAND [6,70,81,85]. A potential disadvantage of our approach is that it has not yet been tested to detect HAND in more advanced stages of the infection. Hence, future additional studies are needed in this direction.

Despite our encouraging results, some limitations are to be acknowledged. First, we only recruited individuals with asymptomatic HIV-1 Infection, which impeded us from 
testing our ARPA-based predictive models for HAND in individuals with symptomatic HIV or AIDS. A second limitation is the sample size. Although we previously showed that a sample of 60 seronegative controls and 60 individuals with HIV-1 Infection has enough power to detect differences between the HIV-infected and control groups across the set of 21 neuropsychological tests administered to all subjects [39], this may not be the case for predictive models. A third limitation is the non-inclusion of other psychological [98], sociocultural/ethnic, or genetic factors that could potentially influence the prediction of HAND in our sample $[15-17,81,82,99]$. Despite these limitations, the clinical variables included in our neuropsychological protocol predict HAND status, with high accuracy, in this community (Figures 1 and 4). As part of an integrative approach, we encourage the use of our short protocol in combination with other methods to detect HAND.

Future similar studies for this topic, especially those of longitudinal nature, should be conducted in Colombia and Latin America. Studies covering all stages of the HIV-1 Infection that include other clinical, medical, virologic, and psychosocial variables associated with HAND, in addition to the neuropsychological evaluation protocol and combination antiretroviral therapy (cART) being used, are needed. As cART are known to contribute to HAND due to the toxicity of these drugs, studies assessing how cART delineates HAND risk and are yet to be explored. Moreover, the identification of biomarkers underpinning HAND susceptibility [100] may be crucial for a better understanding of HAND, and will allow for more accurate diagnosis and follow-ups. This will converge in establishing clinical guidelines for HAND in the developing world [101].

\section{Conclusions}

The proposed HAND short neuropsychological protocol showed an outstanding performance to detect suspicion of HAND in individuals with asymptomatic HIV-1 Infection from an African-admixture community in Barranquilla, Colombia. By using three different operational criteria and developing community-specific cut-off values, we were able to derive normalized data and highly improve the prediction of HAND diagnosis in this population. This short neuropsychological protocol may help to increase the detection accuracy of milder forms of HAND in the clinical setting, and facilitate monitoring neuropsychological functioning, patients' follow-up, and treatment decision making.

Supplementary Materials: The following are available online at https: / www.mdpi.com/article / 10.3390/brainsci11081037/s1, Figure S1: Results of the ARPA-based predictive model for HAND screening using the (a) MMSE, (b) IHDS and (c) MMSE+IHDS criteria; Table S1: Possible results when comparing real and predicted HAND; Table S2: Expressions for calculating the performance measures used to quantitatively compare the performance of the different instruments used to predict HAND using our ARPA-based predictive model.

Author Contributions: Conceptualization, M.M.-B. and V.L.; methodology, M.M.-B., J.I.V. and M.A.B.; software, J.I.V.; validation, M.M.-B., R.G., M.V.P. and V.L.; formal analysis, J.I.V. and M.A.-B.; investigation, M.M.-B., M.R.M.C., J.E.A.-L., R.G., M.V.P. and V.L.; resources, M.M.-B.; data curation, M.M.-B. and J.I.V.; writing—original draft preparation, M.M.-B.; writing—review and editing, M.M.B., J.I.V., M.R.M.C., M.A.-H., J.E.A.-L., R.G., M.V.P., M.A.-B. and V.L.; visualization, J.I.V.; supervision, M.M.-B.; project administration, M.M.-B., R.G., M.V.P. and V.L.; funding acquisition, M.M.-B. All authors have read and agreed to the published version of the manuscript.

Funding: The APC was funded by Universidad Simón Bolívar, Barranquilla, Colombia.

Institutional Review Board Statement: The study was conducted according to the guidelines of the Declaration of Helsinki and/or in accordance with the ethical standards of the institutional and/or national research committee or comparable ethical standards. Because these procedures did not represent any potential risk for the participants, the research team, or the environment, and all information retrieved in this study was kept anonymous, a protocol number was not assigned by our Institutional Review Board. The study was approved by the Universidad de Salamanca Commission. Informed consent was obtained from all individual participants included in the study.

Informed Consent Statement: Informed consent was obtained from all subjects involved in the study. 
Acknowledgments: We express our highest sentiment of appreciation to all patients and their families who voluntarily participated. We also thank Joaquín Piñeros Castillo, Sidis Donado and IPS Medicina Integral at Barranquilla, Colombia, for their invaluable help.

Conflicts of Interest: The authors declare no conflict of interest. The funders had no role in the design of the study; in the collection, analyses, or interpretation of data; in the writing of the manuscript, or in the decision to publish the results.

\section{References}

1. Moral De La Rubia, J.; Segovia Chavez, M. Discrimination Against Women Infected with Human Immunodeficiency Virus (HIV) By Members of Their Own Family. Psicogente 2015, 18, 89-103. [CrossRef]

2. ONUSIDA. Hoja Informativa-Últimas Estadísticas Sobre el Estado de la Epidemia de Sida. 2019. Available online: https: //www.unaids.org/es/resources/fact-sheet (accessed on 30 January 2020).

3. Marin-Webb, V.; Jessen, H.; Kopp, U.; Jessen, A.B.; Hahn, K. Validation of the International HIV Dementia Scale as a Screening Tool for HIV-Associated Neurocognitive Disorders in a German-Speaking HIV Outpatient Clinic. PLoS ONE 2016, 11, e0168225. [CrossRef] [PubMed]

4. Heaton, R.K.; Franklin, D.R.; Ellis, R.J.; McCutchan, J.A.; Letendre, S.L.; Leblanc, S.; Corkran, S.H.; Duarte, N.A.; Clifford, D.B.; Woods, S.P.; et al. HIV-associated neurocognitive disorders before and during the era of combination antiretroviral therapy: Differences in rates, nature, and predictors. J. Neurovirol. 2011, 17, 3-16. [CrossRef] [PubMed]

5. Woods, S.P.; Moore, D.J.; Weber, E.; Grant, I. Cognitive Neuropsychology of HIV-Associated Neurocognitive Disorders. Neuropsychol. Rev. 2009, 19, 152-168. [CrossRef] [PubMed]

6. $\quad$ Eggers, C.; Arendt, G.; Hahn, K.; Husstedt, I.W.; Maschke, M.; Neuen-Jacob, E.; Obermann, M.; Rosenkranz, T.; Schielke, E.; Straube, E.; et al. HIV-1-associated neurocognitive disorder: Epidemiology, pathogenesis, diagnosis, and treatment. J. Neurol. 2017, 264, 1715-1727. [CrossRef]

7. Antinori, A.; Arendt, G.; Becker, J.T.; Brew, B.; Byrd, D.A.; Cherner, M.; Clifford, D.B.; Cinque, P.; Epstein, L.; Goodkin, K.; et al. Updated research nosology for HIV-associated neurocognitive disorders. Neurology 2007, 69. [CrossRef]

8. Joska, J.A.; Witten, J.; Thomas, K.G.; Robertson, C.; Casson-Crook, M.; Roosa, H.; Creighton, J.; Lyons, J.; McArthur, J.; Sacktor, N.C. A Comparison of Five Brief Screening Tools for HIV-Associated Neurocognitive Disorders in the USA and South Africa. AIDS Behav. 2016, 20, 1621-1631. [CrossRef]

9. Heaton, R.K.; Clifford, D.B.; Franklin, D.R.; Woods, S.P.; Ake, C.; Vaida, F.; Ellis, R.J.; Letendre, S.L.; Marcotte, T.D.; Atkinson, J.H.; et al. HIV-associated neurocognitive disorders persist in the era of potent antiretroviral therapy: CHARTER Study. Neurology 2010, 75, 2087-2096. [CrossRef] [PubMed]

10. Oshinaike, O.O.; Akinbami, A.A.; Ojo, O.O.; Ojini, I.F.; Okubadejo, N.; Danesi, A.M. Comparison of the Minimental State Examination Scale and the International HIV Dementia Scale in Assessing Cognitive Function in Nigerian HIV Patients on Antiretroviral Therapy. AIDS Res. Treat. 2012, 2012, 581531. [CrossRef] [PubMed]

11. Kabuba, N.; Menon, J.A.; Franklin, D.R.; Heaton, R.K.; Hestad, K.A. Use of Western Neuropsychological Test Battery in Detecting HIV-Associated Neurocognitive Disorders (HAND) in Zambia. AIDS Behav. 2017, 21, 1717-1727. [CrossRef]

12. Butters, N.; Grant, I.; Haxby, J.; Judd, L.L.; Martin, A.; McClelland, J.; Pequegnat, W.; Schacter, D.; Stover, E. Assessment of Aids-related cognitive changes: Recommendations of the NIMH workshop on neuropsychological assessment approaches. J. Clin. Exp. Neuropsychol. 1990, 12, 963-978. [CrossRef]

13. Maj, M.; Starace, F.; Sartourius, N. Neuropsychiatric aspects of HIV-1 infection: Data collection instrument for a WHO crosscultural study. Organ 1991, 69, 243-245.

14. Grant, I.; Martin, A. Neuropsychology of HIV Infection; Oxford University Press: Oxford, UK, 1994.

15. Pugh, K.; Riccio, M.; Jadresic, D.; Burgess, A.P.; Baldeweg, T.; Catalan, J.; Lovett, E.; Hawkins, D.A.; Gruzelier, J.; Thompson, C. A longitudinal study of the neuropsychiatric consequences of HIV-1 infection in gay men. II. Psychological and health status at baseline and at 12-month follow-up. Psychol. Med. 1994, 24, 897-904. [CrossRef]

16. Ardila-Ardila, A.; Goodkin, K.; Concha-Bartolini, M.; Lecusay-Ruiz, R.; Mellan-Fajardo, S.O.; Suárez-Bustamante, P.; MolinaVásquez, R.; Lee, D.; Chayeb, G.; Wilkie, F.L. HUMANS: A neuropsychological battery for evaluating HIV 1 infected patients. Rev. Neurol. 2003, 36, 756-762. [PubMed]

17. De Almeida, M.; Kamat, R.; Cherner, M.; Umlauf, A.; Ribeiro, C.E.; de Pereira, A.P.; Franklin, D.; Heaton, R.K.; Ellis, R. Improving Detection of HIV-Associated Cognitive Impairment: Comparison of the International HIV Dementia Scale and a Brief Screening Battery. J. Acquir. Immune Defic. Syndr. 2017, 74, 332. [CrossRef]

18. Zipursky, A.R.; Gogolishvili, D.; Rueda, S.; Brunetta, J.; Carvalhal, A.; McCombe, J.A.; Gill, M.J.; Rachlis, A.; Rosenes, R.; Arbess, G.; et al. Evaluation of brief screening tools for neurocognitive impairment in HIV/AIDS: A systematic review of the literature. AIDS 2013, 27, 2385. [CrossRef]

19. Cysique, L.A.; Casaletto, K.B.; Heaton, R.K. Reliably Measuring Cognitive Change in the Era of Chronic HIV Infection and Chronic HIV-Associated Neurocognitive Disorders. In Current Topics in Behavioral Neurosciences; Springer: Berlin/Heidelberg, Germany, 2019; pp. 1-28. [CrossRef]

20. Chan, L.G.; Ho, M.J.; Lin, Y.C.; Ong, Y.; Wong, C.S. Development of a neurocognitive test battery for HIV-associated neurocognitive disorder (HAND) screening: Suggested solutions for resource-limited clinical settings. AIDS Res. Ther. 2019, 16, 9. [CrossRef] 
21. Smail, R.C.; Brew, B.J. HIV-Associated Neurocognitive Disorder. In The Human Hypothalamus: Neuropsychiatric Disorders; Elsevier: Amsterdam, The Netherlands, 2018; Volume 152, pp. 75-97.

22. Power, C.; Selnes, O.A.; Grim, J.A.; McArthur, J.C. HIV Dementia Scale: A Rapid Screening Test. J. Acquir. Immune Defic. Syndr. Hum. Retrovirol. 1995, 8, 273-278. [CrossRef]

23. Sacktor, N.C.; Wong, M.; Nakasujja, N.; Skolasky, R.; Selnes, O.A.; Musisi, S.; Robertson, K.; McArthur, J.C.; Ronald, A.; Katabira, E. The International HIV Dementia Scale: A new rapid screening test for HIV dementia. AIDS 2005, 19, 1367-1374.

24. Antinori, A.; Arendt, G.; Grant, I.; The Mind Exchange Working Group; Letendre, S.; Muñoz-Moreno, J.A.; Eggers, C.; Brew, B.; Brouillette, M.-J. Assessment, Diagnosis, and Treatment of HIV-Associated Neurocognitive Disorder: A Consensus Report of the Mind Exchange Program. Clin. Infect. Dis. 2013, 56, 1004-1017. [CrossRef]

25. Haddow, L.J.; Floyd, S.; Copas, A.; Gilson, R.J.C. A Systematic Review of the Screening Accuracy of the HIV Dementia Scale and International HIV Dementia Scale. PLoS ONE 2013, 8, e61826. [CrossRef]

26. Moore, D.J.; Roediger, M.J.P.; Eberly, L.E.; Blackstone, K.; Hale, B.; Weintrob, A.; Ganesan, A.; Agan, B.K.; Letendre, S.L.; Crum-Cianflone, N.F. Identification of an Abbreviated Test Battery for Detection of HIV-Associated Neurocognitive Impairment in an Early-Managed HIV-Infected Cohort. PLoS ONE 2012, 7, e47310. [CrossRef]

27. Kamminga, J.; Lal, L.; Wright, E.J.; Bloch, M.; Brew, B.J.; Cysique, L.A. Monitoring HIV-Associated Neurocognitive Disorder Using Screenings: A Critical Review Including Guidelines for Clinical and Research Use. Curr. HIV/AIDS Rep. 2017, 14, 83-92. [CrossRef] [PubMed]

28. Pedraza, O.; Mungas, D. Measurement in Cross-Cultural Neuropsychology. Neuropsychol. Rev. 2008, 18, 184-193. [CrossRef] [PubMed]

29. Robertson, K.; Jiang, H.; Evans, S.R.; Marra, C.M.; Berzins, B.; Hakim, J.; Sacktor, N.; Silva, M.T.; Campbell, T.B.; Nair, A.; et al. International neurocognitive normative study: Neurocognitive comparison data in diverse resource-limited settings: AIDS Clinical Trials Group A5271. J. Neurovirol. 2016, 22, 472-478. [CrossRef] [PubMed]

30. Parsons, T.D.; Rogers, S.; Hall, C.; Robertson, K. Motor based assessment of neurocognitive functioning in resource-limited international settings. J. Clin. Exp. Neuropsychol. 2007, 29, 59-66. [CrossRef]

31. McArthur, J.C.; Brew, B. HIV-associated neurocognitive disorders: Is there a hidden epidemic? AIDS 2010, 24, 1367-1370. [CrossRef]

32. Vélez, J.I. Machine Learning based Psychology: Advocating for A Data-Driven Approach. Int. J. Psychol. Res. 2021, 14, 6-11. [CrossRef]

33. Henriquez, M.L.C.; Acosta-Lopez, J.; Martínez-Banfi, M.L.; Vélez, J.I.; Mejia-Segura, E.; Lozano-Gutiérrez, S.G.; Sánchez-Rojas, M.; Zurbarán, M.A.; Zurek, E.E.; Arcos-Burgos, M.; et al. ADHD Endophenotypes in Caribbean Families. J. Atten. Disord. 2018. [CrossRef]

34. Valcour, V.; Pohl, K. Machine Learning to Distinguish HAND from Alzheimer's Disease in HIV over Age 60. 2020. Available online: http:/ / grantome.com/grant/NIH/R01-MH113406-01 (accessed on 4 February 2020).

35. Pluta, A.; Wolak, T.; Sobańska, M.; Gawron, N.; Egbert, A.R.; Szymańska, B.; Horban, A.; Firlag-Burkacka, E.; Bieńkowski, P.; Sienkiewicz-Jarosz, H.; et al. HIV and age underlie specific patterns of brain abnormalities and cognitive changes in high functioning patients. Neuropsychology 2019, 33, 358-369. [CrossRef]

36. Bandera, A.; Taramasso, L.; Bozzi, G.; Muscatello, A.; Robinson, J.A.; Burdo, T.H.; Gori, A. HIV-Associated Neurocognitive Impairment in the Modern ART Era: Are We Close to Discovering Reliable Biomarkers in the Setting of Virological Suppression? Front. Aging Neurosci. 2019, 11, 187. [CrossRef] [PubMed]

37. Cysique, L.; Murray, J.; Dunbar, M.; Jeyakumar, V.; Brew, B.; Cysique, L.; Murray, J. A screening algorithm for HIV-associated neurocognitive disorders. HIV Med. 2010, 11, 642-649. [CrossRef] [PubMed]

38. Breiman, L.; Friedman, J.H.; Olshen, R.A.; Stone, C.J. Classification and Regression Trees; Wadsworth International Group: Belmont, CA, USA, 1984.

39. Martínez-Banfi, M.; Vélez, J.I.; Perea, M.V.; García, R.G.; Puentes-Rozo, P.J.; Chams, M.M.; Ladera, V. Neuropsychological performance in patients with asymptomatic HIV-1 infection. AIDS Care Psychol. Socio-Med. Asp. AIDS/HIV 2018, 30, 623-633. [CrossRef]

40. Betancur, J.; Correa, A.; Estrada; Santiago, E.; Orozco, B.; Velez, H.; Rojas, W.; Borrero, J.; Restrepo, J. Infección Respiratoria en Pacientes con VIH/Sida. En Manual de VIH/SIDA y Otras Infecciones de Transmisión Sexual; Corporación para Investigaciones Biológicas: Medellín, Colombia, 2007.

41. Becker, J.T.; Kingsley, L.A.; Molsberry, S.; Reynolds, S.; Aronow, A.; Levine, A.J.; Martin, E.; Miller, E.N.; Munro, C.A.; Ragin, A.; et al. Cohort Profile: Recruitment cohorts in the neuropsychological substudy of the Multicenter AIDS Cohort Study. Int. J. Epidemiol. 2015, 44, 1506-1516. [CrossRef]

42. Folstein, M.F.; Folstein, S.E.; McHugh, P.R. "Mini-mental state". A practical method for grading the cognitive state of patients for the clinician. J. Psychiatr. Res. 1975, 12, 189-198. [CrossRef]

43. Mungas, D. In-office mental status testing: A practical guide. Geriatrics 1991, 46, 63-66.

44. Folstein, M.F.; Folstein, S.E.; McHugh, P.R. Examen Cognoscitivo Minimental; Adaptación Española; TEA: Madrid, Spain, 2002.

45. Grant, I. The Neurocognitive Complications of HIV Infection. In Encyclopedia of the Human Brain; Ramachandran, V.S., Ed.; Elsevier: Amsterdam, The Netherlands, 2002; pp. 475-489.

46. Weschler, D. Escala de Memoria de Weschler-III; Pearson: Madrid, Spain, 2004. 
47. Rey, A. L'Examen Clinique en Psychologie (The Clinical Psychological Examination); Presse Universitaires de France, Scientific Research Publishing: Paris, France, 1964. Available online: https://www.scirp.org/(S(vtj3fa45qm1ean45vvffcz55))/reference/ referencespapers.aspx?referenceid $=1656248$ (accessed on 2 June 2021).

48. Schmidt, M. Rey Auditory and Verbal Learning Test: A Handbook; Western Psychological Services: Los Angeles, CA, USA, 1996.

49. Spreen, O.; Strauss, E. A Compendium of Neuropsychological Tests, 2nd ed.; Oxford University Press: New York, NY, USA, 1998.

50. Weschler, D. Manual de Aplicación y Corrección de la Escala de Inteligencia de Weschler (WAIS-III); Pearson: Madrid, Spain, 2001.

51. Kaplan, E.; Goddglass, H.; Weintraub, S. Boston Naming Test, 2nd ed.; Pro-Ed: Austin, TX, USA, 2001.

52. Ostrosky-Solis, F.; Ardila, A.; Rosselli, M. Evaluación Neuropsicológica Breve en Español (Neuropsi) [Brief Neuropsychological Evaluation in Spanish (Neuropsi)]; Pearson: Mexico City, Mexico, 1999.

53. Rey, A. Test de Copia y de Reproducción de Memoria de Figuras Geométricas Complejas [Test of Copying and Reproduction of Memory of Complex Geometric Figures], 8th ed.; Lea \& Febiger: Madrid, Spain, 2003.

54. Golden, C.J. Test de Colores y Palabras STROOP [STROOP Test of Colors and Words], 4th ed.; TEA Ediciones: Madrid, Spain, 2005.

55. Spielberger, C.D.; Díaz-Guerrero, R. IDARE. Inventario de Ansiedad: Rasgo-Estado. Manual e Instructivo [Trait-State Anxiety Inventory. Manual and Instruction]; Manual Moderno: Mexico City, Mexico, 1975.

56. R Core Team. R: A Language and Environment for Statistical Computing; R Foundation for Statistical Computing: Vienna, Austria, 2018. Available online: https:/ / www.R-project.org/ (accessed on 30 July 2021).

57. Therneau, B.T.; Atkinson, B.R. Recursive Partitioning and Regression Trees (R Package R Part Version 4.1-15). 2019. Available online: https:/ / cran.r-project.org/web/packages/rpart/index.html (accessed on 27 May 2020).

58. Rao, D.C. CAT scans, PET scans, and genomic scans. Genet. Epidemiol. 1998, 15, 1-18. [CrossRef]

59. Metz, C.E. Basic principles of ROC analysis. Semin. Nucl. Med. 1978, 8, 238-239. [CrossRef]

60. Brin, S.; Motwani, R.; Ullman, J.D.; Tsur, S. Dynamic itemset counting and implication rules for market basket data. ACM SIGMOD Rec. 1997, 26, 255-264. [CrossRef]

61. McNicholas, P.; Murphy, T.B.; O’Regan, M. Standardising the lift of an association rule. Comput. Stat. Data Anal. 2008, 52, 4712-4721. [CrossRef]

62. Moore, R.C.; Paolillo, E.W.; Heaton, A.; Fazeli, P.L.; Jeste, D.V.; Moore, D.J. Clinical utility of the UCSD Performance-Based Skills Assessment-Brief (UPSA-B) in adults living with HIV: Associations with neuropsychological impairment and patient-reported everyday functioning difficulties. PLoS ONE 2017, 12, e0183614. [CrossRef] [PubMed]

63. Goodkin, K.; Hardy, D.J.; Singh, D.; Lopez, E. Diagnostic Utility of the International HIV Dementia Scale for HIV-Associated Neurocognitive Impairment and Disorder in South Africa. J. Neuropsychiatry Clin. Neurosci. 2014, 26, 352-358. [CrossRef]

64. Haddow, L.J.; Laverick, R.; Daskalopoulou, M.; McDonnell, J.; Lampe, F.; Gilson, R.; Speakman, A.; Antinori, A.; Balestra, P.; Bruun, T.; et al. Multicenter European Prevalence Study of Neurocognitive Impairment and Associated Factors in HIV Positive Patients. AIDS Behav. 2017, 22, 1573-1583. [CrossRef] [PubMed]

65. Haynes, B.I.; Pitkanen, M.; Kulasegaram, R.; Casey, S.J.; Schutte, M.; Towgood, K.; Peters, B.; Barker, G.; Kopelman, M.D. HIV: Ageing, cognition and neuroimaging at 4-year follow-up. HIV Med. 2018, 19, 376-385. [CrossRef] [PubMed]

66. Ipser, J.C.; Brown, G.G.; Bischoff-Grethe, A.; Connolly, C.; Ellis, R.; Heaton, R.K.; Grant, I.; Translational Methamphetamine AIDS Research Center (TMARC) Group. HIV Infection Is Associated with Attenuated Frontostriatal Intrinsic Connectivity: A Preliminary Study. J. Int. Neuropsychol. Soc. 2015, 21, 203-213. [CrossRef] [PubMed]

67. Kamat, R.; Doyle, K.L.; Iudicello, J.E.; Morgan, E.E.; Morris, S.; Smith, D.; Little, S.J.; Grant, I.; Woods, S.P. Neurobehavioral Disturbances During Acute and Early HIV Infection. Cogn. Behav. Neurol. 2016, 29, 1-10. [CrossRef]

68. Nabha, L.; Duong, L.; Timpone, J. HIV-associated neurocognitive disorders: Perspective on management strategies. Drugs 2013, 73, 893-905. [CrossRef]

69. Mehta, S.R.; Pérez-Santiago, J.; Hulgan, T.; Day, T.R.C.; Barnholtz-Sloan, J.; Gittleman, H.; Letendre, S.; Ellis, R.; Heaton, R.; Patton, S.; et al. Cerebrospinal fluid cell-free mitochondrial DNA is associated with HIV replication, iron transport, and mild HIV-associated neurocognitive impairment. J. Neuroinflamm. 2017, 14, 72. [CrossRef]

70. Gurgel Fernandes Távora, L.; Martins Figueiredo, T.; Moitas Krammer de Mesquita, R.; Ricarte Bezerra, F.; Pinheiro Aquino, B.; de Baima Colares, J.K. HIV and Dementia: Prevalence and Risk Factors (HIV e Demência: Prevalência e Fatores de Risco VIH y Demencia: Prevalencia y Factores de Riesgo). Rev. Bras. Promoção Saúde 2016, 29, 212-218. [CrossRef]

71. Arango-Lasprilla, J.C.; Rogers, H.; Lengenfelder, J.; DeLuca, J.; Moreno, S.; Lopera, F. Cortical and subcortical diseases: Do true neuropsychological differences exist? Arch. Clin. Neuropsychol. 2006, 21, 29-40. [CrossRef]

72. Dwyer, R.; Wenhui, L.; Cysique, L.; Brew, B.; Lal, L.; Bain, P.; Wesselingh, S.; Wright, E. Symptoms of depression and rates of neurocognitive impairment in HIV positive patients in Beijing, China. J. Affect. Disord. 2014, 162, 89-95. [CrossRef]

73. Maruff, P.; Thomas, E.; Cysique, L.; Brew, B.; Collie, A.; Snyder, P.; Pietrzak, R.H. Validity of the CogState Brief Battery: Relationship to Standardized Tests and Sensitivity to Cognitive Impairment in Mild Traumatic Brain Injury, Schizophrenia, and AIDS Dementia Complex. Arch. Clin. Neuropsychol. 2009, 24, 165-178. [CrossRef]

74. Lopardo, G.D.; Bissio, E.; Iannella, M.D.C.; Crespo, A.D.; Garone, D.B.; Cassetti, L.I. Good Neurocognitive Performance Measured by the International HIV Dementia Scale in Early HIV-1 Infection. J. Acquir. Immune Defic. Syndr. 2009, 52, 488-492. [CrossRef]

75. Abusamra, V.; Abusamra, L.; Sampedro, B.; Difalcis, M.; Martínez, G.; Dávolos, J.M.; Ferreres, A. Trastornos cognitivos en pacientes VIH-1: La dimensión pragmática de la comunicación verbal. Rev. Neuropsicol. Latinoam. 2014, 6, 22-30. [CrossRef] 
76. Bloch, M.; Kamminga, J.; Jayewardene, A.; Bailey, M.; Carberry, A.; Vincent, T.; Quan, D.; Maruff, P.; Brew, B.; Cysique, L. A Screening Strategy for HIV-Associated Neurocognitive Disorders That Accurately Identifies Patients Requiring Neurological Review. Clin. Infect. Dis. 2016, 63, 687-693. [CrossRef] [PubMed]

77. Robbins, R.N.; Joska, J.; Thomas, K.G.F.; Stein, D.; Linda, T.; Mellins, C.A.; Remien, R.H. Exploring the Utility of the Montreal Cognitive Assessment to Detect HIV-Associated Neurocognitive Disorder: The Challenge and Need for Culturally Valid Screening Tests in South Africa. Clin. Neuropsychol. 2013, 27, 437-454. [CrossRef]

78. Amusan, P.; Power, C.; Gill, M.J.; Gomez, D.; Johnson, E.; Rubin, L.H.; Fujiwara, E. Lifetime antiretroviral exposure and neurocognitive impairment in HIV. J. Neurovirol. 2020, 26, 743-753. [CrossRef]

79. Nightingale, S.; Winston, A.; Letendre, S.; Michael, B.; McArthur, J.C.; Khoo, S.; Solomon, T. Controversies in HIV-associated neurocognitive disorders. Lancet Neurol. 2014, 13, 1139-1151. [CrossRef]

80. Tedaldi, E.M.; Minniti, N.L.; Fischer, T. HIV-Associated Neurocognitive Disorders: The Relationship of HIV Infection with Physical and Social Comorbidities. BioMed Res. Int. 2015, 2015, 641913. [CrossRef]

81. Fogel, G.B.; Lamers, S.L.; Levine, A.J.; Valdes-Sueiras, M.; McGrath, M.S.; Shapshak, P.; Singer, E.J. Factors related to HIVassociated neurocognitive impairment differ with age. J. Neurovirol. 2014, 21, 56-65. [CrossRef] [PubMed]

82. Jia, P.; Zhao, Z.; Hulgan, T.; Bush, W.; Samuels, D.; Bloss, C.; Heaton, R.K.; Ellis, R.; Schork, N.; Marra, C.M.; et al. Genome-wide association study of HIV-associated neurocognitive disorder (HAND): A CHARTER group study. Am. J. Med. Genet. Part B Neuropsychiatr. Genet. 2017, 174, 413-426. [CrossRef]

83. McDonnell, J.; Haddow, L.; Daskalopoulou, M.; Lampe, F.; Speakman, A.; Gilson, R.; Phillips, A.; Sherr, L.; Wayal, S.; Harrison, J.; et al. Minimal Cognitive Impairment in UK HIV-Positive Men Who Have Sex with Men: Effect of Case Definitions and Comparison with the General Population and HIV-Negative Men for the Cognitive Impairment in People with HIV in the European Region (CIPHER) Study Group. J. Acquir. Immune Defic. Syndr. 2014, 67, 120-127. [CrossRef]

84. Sacktor, N.; Robertson, K. Evolving clinical phenotypes in HIV-associated neurocognitive disorders. Curr. Opin. HIV AIDS 2014, 9, 517-520. [CrossRef]

85. Focà, E.; Magro, P.; Motta, D.; Compostella, S.; Casari, S.; Bonito, A.; Brianese, N.; Ferraresi, A.; Rodari, P.; Pezzoli, M.C.; et al. Screening for Neurocognitive Impairment in HIV-Infected Individuals at First Contact after HIV Diagnosis: The Experience of a Large Clinical Center in Northern Italy. Int. J. Mol. Sci. 2016, 17, 434. [CrossRef]

86. Sanmarti, M.; Ibáñez, L.; Huertas, S.; Badenes, D.; Dalmau, D.; Slevin, M.; Krupinski, J.; Popa-Wagner, A.; Jaen, A. HIV-associated neurocognitive disorders. J. Mol. Psychiatry 2014, 2, 2. [CrossRef] [PubMed]

87. García-Torres, A.; Vergara-Moragues, E.; Piñón-Blanco, A.; Pérez-García, M. Alteraciones neuropsicológicas en pacientes con VIH e historia previa de consumo de sustancias. Un estudio preliminar. Rev. Latinoam. Psicol. 2015, 47, 213-221. [CrossRef]

88. Nichols, M.J.; Gates, T.M.; Soares, J.R.; Moffat, K.J.; Rae, C.; Brew, B.J.; Cysique, L.A. Atrophic brain signatures of mild forms of neurocognitive impairment in virally suppressed HIV infection. AIDS 2019, 33, 55-66. [CrossRef] [PubMed]

89. Chalermchai, T.; Valcour, V.; Sithinamsuwan, P.; Pinyakorn, S.; Clifford, D.; Paul, R.H.; Tipsuk, S.; Fletcher, J.L.K.; DeGruttola, V.; Ratto-Kim, S.; et al. Trail Making Test A improves performance characteristics of the International HIV Dementia Scale to identify symptomatic HAND. J. Neurovirol. 2013, 19, 137-143. [CrossRef] [PubMed]

90. Skinner, S.; Adewale, A.; DeBlock, L.; Gill, M.J.; Power, C. Neurocognitive screening tools in HIV/AIDS: Comparative performance among patients exposed to antiretroviral therapy. HIV Med. 2009, 10, 246-252. [CrossRef]

91. De Souza, E.M.; Buoniconti, C.S.; Valim, F.; Moura, A.S. Risk factors for neurocognitive impairment in HIV-infected patients and comparison of different screening tools. Dement. Neuropsychol. 2016, 10, 42-46. [CrossRef] [PubMed]

92. Arentoft, A.; Byrd, D.; Robbins, R.N.; Monzones, J.; Miranda, C.; Rosario, A.; Coulehan, K.; Fuentes, A.; Germano, K.K.; D'Aquila, E.; et al. Multidimensional effects of acculturation on English-language neuropsychological test performance among HIV+ Caribbean Latinas/os. J. Clin. Exp. Neuropsychol. 2012, 34, 814-825. [CrossRef] [PubMed]

93. Alford, K.; Banerjee, S.; Nixon, E.; O’Brien, C.; Pounds, O.; Butler, A.; Elphick, C.; Henshaw, P.; Anderson, S.; Vera, J.H. Assessment and Management of HIV-Associated Cognitive Impairment: Experience from a Multidisciplinary Memory Service for People Living with HIV. Brain Sci. 2019, 9, 37. [CrossRef] [PubMed]

94. Clifford, D.B.; Ances, B.M. HIV-Associated Neurocognitive Disorder (HAND). Lancet Infect. Dis. 2013, 13, 976-986. [CrossRef]

95. Croucher, A.; Winston, A. Neurological complications of HIV. Medicine 2013, 41, 450-455. [CrossRef]

96. Barragan Duarte, J.L. Mapa Genético de los Colombianos. Unimedios. 2007. Available online: http://historico.unperiodico.unal. edu.co/ediciones/105/15.html (accessed on 20 April 2021).

97. Cysique, L.A.; Heaton, R.K.; Kamminga, J.; Lane, T.; Gates, T.M.; Moore, D.M.; Hubner, E.; Carr, A.; Brew, B. HIV-associated neurocognitive disorder in Australia: A case of a high-functioning and optimally treated cohort and implications for international neuroHIV research. J. Neurovirol. 2014, 20, 258-268. [CrossRef]

98. Mebarak, M.; De Castro, A.; Salamanca, M.P.; Quintero, M.F. Salud mental: Un abordaje desde la perspectiva actual de la psicología de la salud. Psicol. desde el Caribe 2009, 23, 83-112.

99. Marquine, M.J.; Heaton, A.; Johnson, N.; Rivera-Mindt, M.; Cherner, M.; Bloss, C.; Hulgan, T.; Umlauf, A.; Moore, D.J.; Fazeli, P.; et al. Differences in Neurocognitive Impairment among HIV-Infected Latinos in the United States. J. Int. Neuropsychol. Soc. 2018, 24, 163-175. [CrossRef] 
100. Saylor, D.; Dickens, A.; Sacktor, N.; Haughey, N.; Slusher, B.; Pletnikov, M.; Mankowski, J.L.; Brown, A.; Volsky, D.J.; McArthur, D.S.; et al. HIV-associated neurocognitive disorder-Pathogenesis and prospects for treatment. Nat. Rev. Neurol. 2016, 12, 234-248. [CrossRef]

101. Parry, S.; Zetler, S.; Kentridge, A.; Petrak, J.; Barber, T.; Kentridge, A. Simple screening for neurocognitive impairment in routine HIV outpatient care: Is it deliverable? AIDS Care 2017, 29, 1275-1279. [CrossRef] 